\title{
Bioinspired Non-Heme Iron Complexes: The Evolution of Facial $N, N, O$ Ligand Design
}

\author{
Emily C. Monkcomª, Pradip Ghosha, Emma Folkertsmaa , Hidde A. Negenmanª, Martin Lutz ${ }^{\mathrm{b}}$, \\ and Robertus J. M. Klein Gebbink ${ }^{\mathrm{a} *}$
}

\begin{abstract}
Iron-containing metalloenzymes that contain the 2-His-1-Carboxylate facial triad at their active site are well known for their ability to activate molecular oxygen and catalyse a broad range of oxidative transformations. Many of these reactions are synthetically challenging, and developing small molecular iron-based catalysts that can achieve similar reactivity and selectivity remains a long-standing goal in homogeneous catalysis. This review focuses on the development of bioinspired facial $N, N, O$ ligands that model the 2-His-1-Carboxylate facial triad to a greater degree of structural accuracy than many of the polydentate $\mathrm{N}$-donor ligands commonly used in this field. By developing robust, well-defined $N, N, O$ facial ligands, an increased understanding could be gained of the factors governing enzymatic reactivity and selectivity.
\end{abstract}

Keywords: Bioinspired metal complexes $\cdot 2$-His-1-Carboxylate facial triad $\cdot$ N,N,O Ligands $\cdot$ Non-heme iron

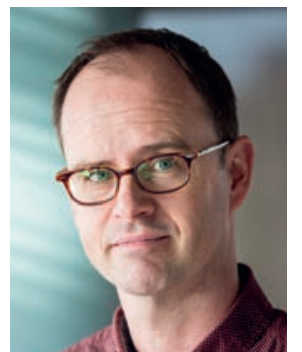

Robertus (Bert) J.M. Klein Gebbink obtained a $\mathrm{PhD}$ in supramolecular and bioinorganic chemistry under the guidance of Roeland Nolte in 1998. After postdoctoral studies at Stanford University (USA), he accepted a senior postdoctoral position at Utrecht University (NL) with Prof. Gerard van Koten in 1999. Climbing the ranks, he was promoted to full professor of Homogeneous and Bioinspired Catalysis at Utrecht in 2006. In the past years he acted as head of the chemistry department at Utrecht and as the coordinator of the European initial training network NoNoMeCat on Non-Noble Metal Catalysis.

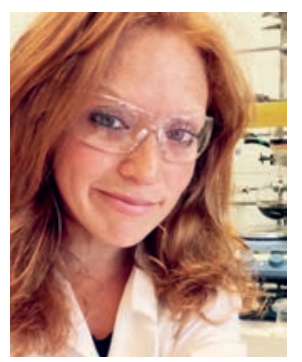

Emily C. Monkcom was born in 1992 in Brussels, Belgium. She completed her school education at the European School of Brussels in 2010 and started her undergraduate studies at Imperial College London (UK) the same year. She obtained her MSci degree in chemistry (with a year in industry) in 2015. Since 2016, she has been pursuing a $\mathrm{PhD}$ with Prof. Bert Klein Gebbink in the Organic Chemistry and Catalysis (OCC) group at Utrecht University (NL). Her project is focused on developing new bioinspired iron complexes that model mononuclear non-heme iron enzyme active sites.

\section{Introduction: Bioinorganic Chemistry}

Bioinorganic chemistry is a vibrant and flourishing field, poised at the interface of chemistry and biology. Its primary focus is the study of the inorganic matter of life - that is to say, the metal-containing proteins and enzymes, as well as the biologically relevant metal complexes that enable metabolic processes to occur. Indeed, metal sites in biology enable some of the most challenging and consequential reactions on Earth, ranging from oxygen transport in animals to photosynthesis in plants and nitrogen-fixation in bacteria. This astounding breadth of reactivity involves attractive features such as small molecule activation and late-stage functionalization, all of which are achieved under physiological conditions and with exquisite stereo- and regioselectivity. For bioinorganic chemists, the direct deployment, engineering or mimicry of metalloenzymes and metal-containing biomolecules for research and commercial applications holds great potential for improving the green credentials of today's chemical industry.

Although it has long been known that metals play a central role in biological function, it was not until the mid- $20^{\text {th }}$ century that bioinorganic chemistry emerged as an independent field, fuelled by advancements in enzymology, protein crystallography, spectroscopy, bioinformatics, and computational chemistry. ${ }^{[1-4]}$ Combined, these techniques enabled scientists to use a molecular approach in their analysis of the structural and electronic factors dictating the function of a biologically relevant metal site (also known as the 'structure-function relationship'). [5] This is best exemplified by iron. For over 300 years, iron has been known to be a key component of mammalian blood, but it was not until 1959, thanks to the pioneering work of Kendrew and Perutz, that the molecular structure of the metalloprotein haemoglobin was elucidated, thereby revealing the exact coordination chemistry involved in the uptake of oxygen by the iron nucleus. ${ }^{[6,7]}$

Gaining a molecular perspective on the active sites of metalloenzymes is perhaps the most important and revolutionary concept in the development of bioinorganic chemistry. Indeed, active site structure elucidation has injected renewed vigour and stimulated novel approaches in the field of coordination chemistry as a direct consequence of metal-containing biomolecules now being regarded as elaborate inorganic metal complexes. ${ }^{[5]}$ Using this molecular perspective, bioinorganic chemists continue to extract the general principles underlying catalysis by metalloenzymes, and marry them with the known coordination chemistry of synthetic 
transition metal complexes. As a result, a multitude of different disciplines now exists within the field of bioinorganic chemistry, ranging from the incorporation of abiotic metals in artificial metalloenzymes, to the development of medical imaging agents, and the design of synthetic biomimetic complexes as novel industrial catalysts.

Overall, it is estimated that approximately half of all structurally characterised enzymes require one or more metal centres to carry out their function. ${ }^{[8]}$ Furthermore, most metalloenzymes function with only a specific metal ion or cluster, embedded within the protein scaffold by a complex assembly of ligands whose electronic properties are tuned to hosting that particular metal ion. Too little of a particular metal can deprive a metalloenzyme of its active metal centre; too much can force metal promiscuity in other metal-dependent biomolecules, blocking their function. ${ }^{[9]}$ This stringent metal selectivity and the accompanying ligand architecture is closely linked to the evolution of metalloenzymes from the primordial soup, dictated by the response of species to massive environmental changes such as shifts in ocean acidity and metal solubility. Consequently, one of the central challenges of bioinorganic chemistry is the delineation of the biosynthetic mechanisms through which metalloenzymes arose, as these are fundamental to the understanding of our origins.

\section{The 2-His-1-Carboxylate Facial Triad}

The 2-His-1-Carboxylate facial triad (2H1C) is a bioinorganic motif that occurs at the active site of many oxygen-activating mononuclear non-heme iron enzymes, and is currently regarded as one of the most versatile platforms with which Nature catalyses oxidative transformations. It has attracted particular interest from the bioinorganic and catalysis communities due to its ability to activate molecular oxygen and mediate an astoundingly diverse scope of oxidative transformations, including hydroxylation, cis-dihydroxylation, epoxidation, ring-opening, ring-closing and epimerization reactions, in a highly stereo- and regioselective manner. ${ }^{[10,11]}$

The $2 \mathrm{H} 1 \mathrm{C}$ is characterized by the facial, tripodal coordination of two neutral histidine (His) residues and an anionic carboxylate group, typically an aspartate (Asp) or glutamate residue (Glu), to an iron(II) centre. Together, these form a so-called ' $N, N, O$ ' coordination motif. Using its remaining coordination sites, the iron can accommodate up to three different exogenous ligands on the opposite face of its coordination sphere. During the enzyme's resting state, these sites are typically occupied by labile water molecules (Fig. 1, left).

So far, the $2 \mathrm{H} 1 \mathrm{C}$ has been identified at active site of five different sub-classes of mononuclear non-heme iron enzymes, categorised according to their specific mechanistic requirements. These are: 1$)$ the $\alpha$-ketoglutarate ( $\alpha \mathrm{KG})$ dependent enzymes, 2 ) the extradiol ring-cleaving dioxygenases, 3 ) the pterin-dependent hydroxylases, 4) the Rieske dioxygenases, and 5) the cofactor-in- dependent oxidase enzymes. These enzyme sub-classes have been extensively reviewed elsewhere, ${ }^{[2,3]}$ and will therefore not be discussed exhaustively here. Despite exhibiting very different reactivities, the different sub-classes of enzymes share some common mechanistic features, which are depicted schematically in Fig. 1 (right). The first step generally involves the binding of a substrate or co-substrate molecule to the active site cavity, often directly to the iron nucleus. This displaces one or more of the loosely bound water molecules from the resting state (A) and generates a coordinatively unsaturated iron(II) centre (B), which is primed to react with dioxygen. The binding of dioxygen occurs directly to iron, cis to the (co)substrate $(\mathbf{C})$ and trans to one of the three constituent residues of the $2 \mathrm{H} 1 \mathrm{C}$. The different trans effects exerted by a neutral histidine or an anionic carboxylate group have been proposed as playing an important role in modulating the reactivity of the bound dioxygen. ${ }^{[10,12,13]}$ Dioxygen is then reduced to the peroxide level (D), after which the mechanisms for the various iron enzymes diverge significantly. In general, the $\mathrm{O}-\mathrm{O}$ bond is cleaved and a high valent iron-oxo complex $(\mathbf{E})$ is generated, considered as being the true oxidizing species. Direct evidence for a high valent iron-oxo intermediate has been reported for several different types of mononuclear non-heme iron enzymes. ${ }^{[11,14-16]}$

The flexibility in coordination chemistry enabled by the $2 \mathrm{H} 1 \mathrm{C}$ is best exemplified by the different crystal structures of the enzyme-substrate complexes for enzymes such as 2,3-homoprotocatechuate dioxygenase (2,3-HPCD), taurine dioxygenase (TauD), and isopenicillin N synthase (IPNS), depicted in Fig. 2. In 2,3-HPCD, an extradiol catechol cleaving dioxygenase enzyme, the catechol substrate binds as a bidentate ligand and one vacant site trans to the Glu residue is available for dioxygen binding. ${ }^{[18]}$ In TauD, an $\alpha \mathrm{KG}$-dependent monohydroxylase enzyme, the $\alpha \mathrm{KG}$ cofactor binds directly to the iron centre in a bidentate fashion and the substrate (taurine) docks within the active site cavity, in close proximity to the metal centre. One vacant site remains available for dioxygen binding, trans to a His residue. ${ }^{[19]}$ In IPNS, a cofactor-independent oxidase enzyme, the tripeptidic thiolate substrate $\delta$-(L- $\alpha$-aminoadipoyl)-L-cysteine-D-valine (ACV) binds as a monodentate ligand directly to the iron centre, and one of the loosely bound water molecules remains bound to the iron centre as a spectator ligand. One vacant site remains available for dioxygen binding, trans to the Asp residue. ${ }^{[20]}$

Central to the ability of mononuclear non-heme iron enzymes to activate and utilise molecular oxygen is the spin state of the iron centre during all stages of catalysis. ${ }^{[21,22]}$ In its electronic ground state, dioxygen exists in an open-shell triplet state $\left({ }^{3} \mathrm{O}_{2}\right)$ with two unpaired electrons $(S=1)$. In contrast, organic molecules typically exist in a closed-shell singlet ground state with no unpaired electrons $(S=0)$, rendering their spontaneous reaction with $\mathrm{O}_{2}$ sluggish and kinetically unfavourable due to the spin mismatch. Iron is capable of circumventing this spin mismatch by coordinating directly to ${ }^{3} \mathrm{O}_{2}$ and activating it (reductively) to form
Fig. 1. Left: the 2-His-1Carboxylate facial triad at the active site of deacetoxycephalosporin $\mathrm{C}$ synthase (DAOCS) from Streptomyces clavuligerus (PDB 1RXF). ${ }^{[17]}$ Right: generalized mechanistic pathway for the aerobic oxidation of substrates at nonheme iron enzyme active sites that contain the $2 \mathrm{H} 1 \mathrm{C}$. Figure adapted from Que et al..$^{[11]}$
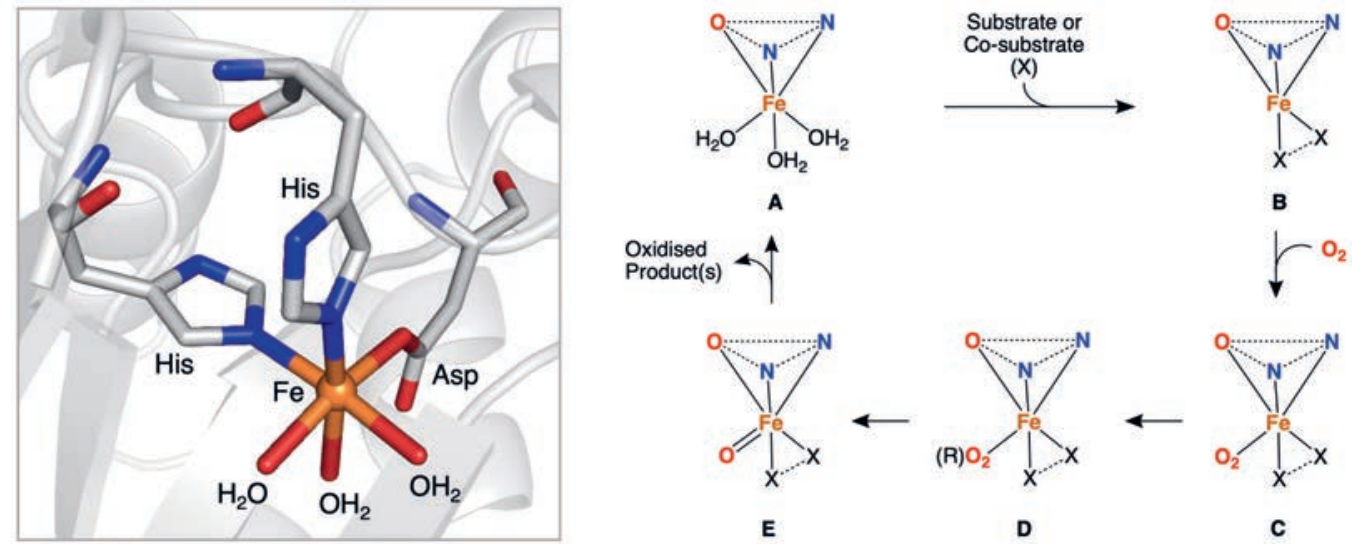

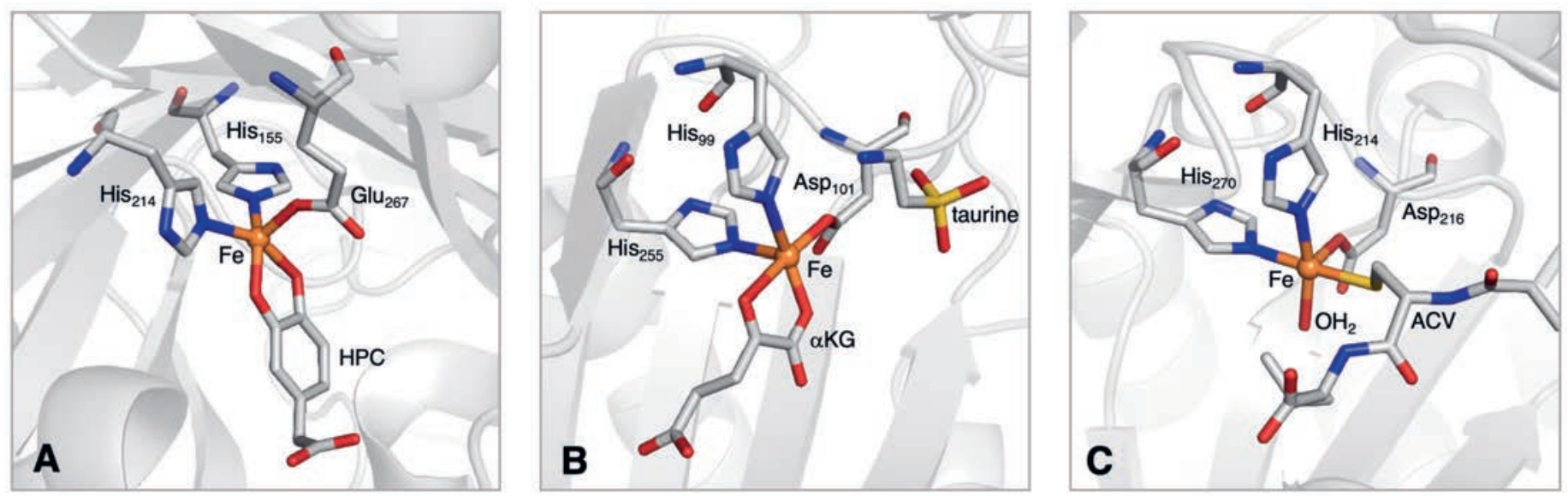

Fig. 2. The substrate-bound active sites for A) 2,3-HPCD (PDB 1Q0C), ${ }^{[18]}$ B) TauD (PDB 1OS7), ${ }^{[19]}$ and C) IPNS (PDB 1BK0). ${ }^{[20]}$ Carbon, iron, nitrogen, oxygen and sulphur are depicted in grey, blue, red and yellow, respectively.

a reactive singlet $\left(\mathrm{O}_{2}^{-}\right)$or doublet $\left(\mathrm{O}_{2}^{2-}\right)$ species. Typically, 2H1Ccontaining iron enzymes contain a ferrous ion $\left(\mathrm{d}^{6}\right)$ in their resting state, which exists in a high spin electronic configuration $(S=2)$.

The 2H1C has fascinated the bioinorganic community for many years and much research has been undertaken to elucidate its role in determining the reactivity and selectivity of enzymes compared to other non-heme iron enzymes such as the thiol dioxygenases that contain the 3 -His facial triad (3His) at their active site, which do not require the trans effect of a carboxylate group. ${ }^{[13,23,24]}$ One of the strategies to gain further insight into the active sites of mononuclear non-heme iron enzymes is to study biomimetic nonheme iron complexes that replicate some of the structural features of the first coordination sphere of the enzyme active site.

\section{Bioinspired Facial $N, N, O$ Ligand Design}

The $2 \mathrm{H} 1 \mathrm{C}$ has served as the founding architectural model for many polydentate $\mathrm{N}$-donor ligands, ${ }^{[25]}$ some of the most wellknown being the Tp(tris(pyrazolyl)borate), ${ }^{[26]} \mathrm{Me}_{3} \mathrm{TACN}(1,4,7$-trimethyl-1,4,7-triazacyclononane),[27] TPA (tris(2-pyridylmethyl) amine). [28-30] TQA (tris(2-quinolylmethyl)amine), [31] ${ }^{[3 N M e}$ (4,7,10-trimethyl-1,4,7,10-tetraaza-2,6-pyridinophane $)^{[32]}$ and BPMEN (bis(2-pyridylmethyl)-1,2-diaminoethane) ${ }^{[33]}$ lig- ands. These ligands coordinate in a 1:1 stoichiometry with iron and support the formation of non-heme high-valent iron-oxo species. However, these ligands could arguably be considered closer in structure to the $3 \mathrm{His}$ than the $2 \mathrm{H} 1 \mathrm{C}$, due to the presence of only $\mathrm{N}$-donors and the lack of an anionic $O$-donor. For modelling the reactivity of IPNS, for example, this may present itself as a drawback. Furthermore, many of these ligands have a denticity greater than three, which deviates from the tricoordinate nature of the $2 \mathrm{H} 1 \mathrm{C}$.

In order to model the $2 \mathrm{H} 1 \mathrm{C}$ with a greater degree of structural accuracy, it remains of great interest to develop tridentate $\mathrm{N}, \mathrm{N}, \mathrm{O}$ ligands that can coordinate to an iron centre in a facial manner while leaving cis-orientated coordination sites available for (co-) substrates to bind and reactions to take place. Two major challenges accompany this ligand design. Firstly, the connectivity of the ligand should promote facial ( fac) coordination in a manner rather than meridional (mer) coordination (Fig. 3). Typically, tripodal ligand designs that involve a central connecting atom are more likely to achieve facial coordination than linear ones. Secondly, the coordination of two ligand equivalents to an iron centre should be prevented, as this results in the formation of coordinatively saturated bisligated complexes that are generally unreactive.

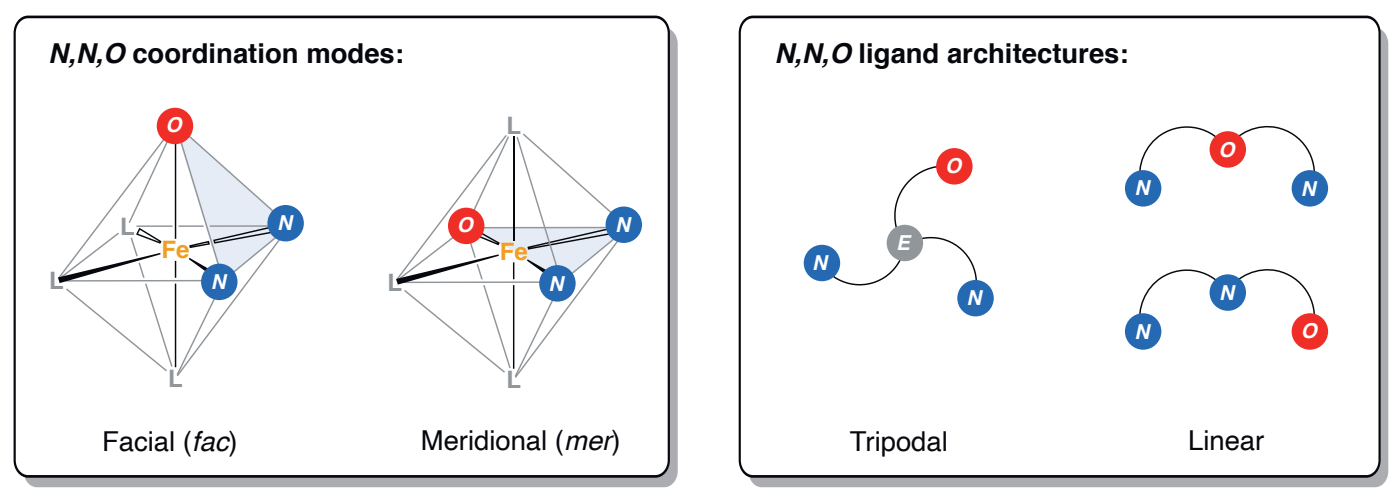

Fig. 3. Left: schematic representation of the facial (fac) and meridional (mer) coordination modes of a tridentate $N, N, O$ ligand $(\mathrm{L}=$ exogenous ligand). Right: simplified representation of tripodal and linear $N, N, O$ ligand designs $(E=$ $B, C, N)$. Bottom: a list of different constituent $\mathrm{N}$ - and $\mathrm{O}$-donor groups that have been used in $N, N, O$ ligand design $(\mathrm{R}=$ organic substituent).

Examples of $\mathrm{N}$-donor and O-donor groups:

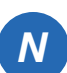<smiles>[R]c1cccc(C)n1</smiles><smiles>[R]c1nc(C)n([R])c1[R]</smiles><smiles>[R]c1nn([3H])c([R])c1[R]</smiles><smiles>F[Y]n1cncn1</smiles><smiles>[R]c1nn([3H])nc1[R]</smiles><smiles>CN1CCCC1C(=O)C(C)(C)C</smiles>
$\sum_{2}^{\mathrm{N}} \mathrm{l}_{\mathrm{R}}^{\mathrm{R}}$<smiles>[R]c1cc([R])c([O-])c(C)c1</smiles>
象
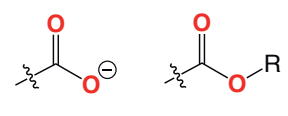<smiles>[Y]C(=O)NP</smiles>
$30^{\ominus}$ 
Numerous examples of $N, N, O$ ligands can be found in the literature, where the nature of constituent donor groups has been systematically varied.[34-37] By modifying the two $N$-donors and any of their tethered organic substituents, the steric or electronic properties of the ligands can easily be tuned. In some cases, two different $\mathrm{N}$-donors have been installed, thereby imparting chirality to the ligand scaffold. ${ }^{[38,39]}$ Other studies have also focused on varying the nature of the central connecting atom. Incorporating a central borohydride group, for example, can lead to similar ligand properties and coordination chemistry to the well-known Tp ligand family. ${ }^{[40,41]}$ Alternatively, incorporating a central nitrogen atom generally results in a tetradentate tripodal ligand framework, not unlike the TPA ligand scaffold. ${ }^{[42,43]}$

However, despite the diversity in $N, N, O$ ligand designs, the number of ligands that can provide a facial $N, N, O$ triad and support the formation of mononuclear, monoligated metal complexes is small. Typically, difficulties in achieving the desired coordination mode are encountered due to the formation of bisligated complexes, bridging coordination modes of an anionic $O$-donor, or lability of a neutral $O$-donor. The primary strategy to overcome these issues has been to increase the ligand's steric demand and bite angle by, for example, increasing the size of the $\mathrm{N}$-/O-donor groups or by increasing the length of the organic linkers between donor group. In some cases, mono-ligation has been achieved with sterically less demanding ligands by using a co-ligand.

The typically weak-field nature of an $N, N, O$ ligand's donor set generally results in the formation of high spin non-heme iron complexes. Although this is in line with the high-spin electronic states of $2 \mathrm{H} 1 \mathrm{C}$-containing enzyme active sites, the paramagnetic nature of these complexes can pose challenges for the synthetic inorganic chemist. For instance, the occupancy of non-bonding or antibonding orbitals in high spin $(S=2)$ non-heme iron(II) complexes is higher compared to intermediate spin $(S=1)$ or low spin $(S=0)$ iron(II) complexes. ${ }^{[22]}$ This has the effect of increasing the $\mathrm{Fe}-\mathrm{N}$ bond distances, for example, and may result in an increased lability of the $N, N, O$ ligand donor set.[21] Spectroscopically, the paramagnetic nature of high spin iron complexes requires the use of specialized spectroscopic methods (e.g. ${ }^{57} \mathrm{Fe}$ Mössbauer spectroscopy, X-ray absorption spectroscopy, MCD/CD, EPR, Evans NMR method and X-ray crystallography) in order to make an accurate description of their electronic structure, with computational studies often made to support these assignments. From a practical point of view, the (often) high reactivity of the iron complexes to $\mathrm{O}_{2}$ necessitates careful handling (e.g. Schlenk line and glovebox techniques) under inert atmosphere conditions.

Some of the most notable $N, N, O$ ligand contributions and corresponding non-heme iron complexes derive from the groups of Que, ${ }^{[44]}$ Burzlaff, ${ }^{[45]}$ Rutledge, ${ }^{[46]}$ Carrano ${ }^{[47]}$ andKlein Gebbink. ${ }^{[3.35]}$ The recent advances in $N, N, O$ ligand design and coordination chemistry from our group will be further described in the next sections of this review.

\section{The Evolution of BAIP Facial $N, N, O$ Ligands}

In the quest for robust structural models of the $2 \mathrm{H} 1 \mathrm{C}$, our group has focused on the development of a series of $N, N, O$ li- gands derived from 3,3-bis(1-alkylimidazol-2-yl)propionic acid (BAIP). These ligands are tripodal in nature and comprise two imidazole $\mathrm{N}$-donors and an $\mathrm{O}$-donor, joined together in a heteroscorpionate fashion by means of a central carbon atom. The nature of the $O$-donor group can be systematically varied to be either a carboxylic acid, an ester, an amide, or a phenol group (Fig. 4). Carboxylic acids can easily be converted to their anionic carboxylate form and are, therefore, the most relevant moiety with which to model the $2 \mathrm{H} 1 \mathrm{C}$, both structurally and electronically. Esters and secondary amide groups coordinate by means of their carbonyl group as neutral $O$-donors, but have the advantage of incorporating an additional organic substituent that can modulate the electronic properties of the carbonyl group and increase the steric bulk of the $O$-donor. Phenols are an attractive means with which to achieve anionic $O$-donor coordination while simultaneously having the option to tune the steric and electronic properties of the phenol ring by means of its ortho- and para-substituents $\left(\mathrm{R}^{4}\right)$. However, phenolates are known to be redox-active, which deviates somewhat from the carboxylate group of the $2 \mathrm{H} 1 \mathrm{C}$. Finally, the steric properties of the imidazoles themselves can be tuned by varying the nature of the organic substituent on the 1-, 4- and 5-positions of the heterocycle $\left(\mathrm{R}^{1}, \mathrm{R}^{2}\right.$ and $\left.\mathrm{R}^{3}\right)$. In general, the ligands used in our group require the imidazoles to always be functionalised on their 1-positions $\left(\mathrm{R}^{1}\right)$.

\subsection{Synthesis}

The synthesis of the different types of $N, N, O$ ligands used in our group is schematically represented in Fig. 5. Carboxylic acid, ester and amide ligands derive from the same synthetic pathway. Starting from the desired 1-alkyl(benz)imidazole precursor, the first step involves the formation of a bis-imidazole ketone moiety (A), which can be reduced with hydrazine to afford the bis-imidazole methane scaffold (B). Alternatively, $N^{1}$,3-dialkyllbenzene 1,2-diamine precursors $(\mathbf{C})$ can undergo a double cyclization condensation reaction with diethyl malonate to form bis-(1,4-dialkyl)benzimidazole methane scaffolds. From here, the synthesis of esters or amides can easily be achieved by deprotonating the methylene bridge with $n$-BuLi, and reacting it with one equivalent of the desired alkyl 2-bromoacetate or 2-bromo- $N$-alkylacetamide precursor, respectively. The carboxylic acid ligands can conveniently be synthesised from the hydrolysis of the ester ligands. Phenol ligands are also conveniently synthesised from different 1-alkyl(benz)imidazole precursors, using a synthetic route previously described by Jameson et al. ${ }^{[48]}$ The synthesis starts with the deprotonation of imidazole using $n-\mathrm{BuLi}$, after which the lithium imidazolium salt is reacted with a hydroxy-protected methyl salicylate in a 2:1 stoichiometry. The resulting tertiary alcohol (D) is subsequently methylated (E), before deprotection of the phenol, thereby ensuring that the phenol is the only site that can be deprotonated for subsequent coordination chemistry.

\subsection{Carboxylate Ligands}

The family of BAIP-derived carboxylate ligands was designed with the incorporation of a simple carboxylic acid group, which can easily be deprotonated to generate the respective carboxylate. As previously mentioned, this can be regarded as the most electronically and structurally faithful group with which to model the
Fig. 4. Facial $N, N, O$ ligand designs employed in the Klein Gebbink group.
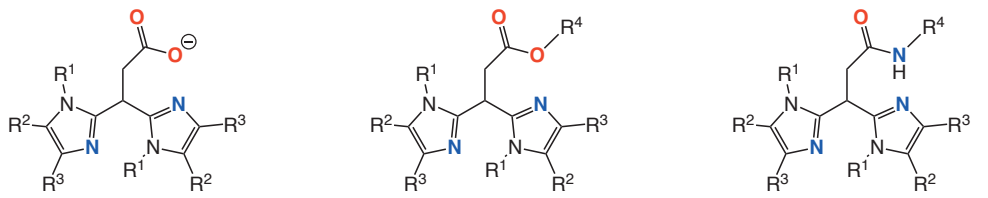

Amide

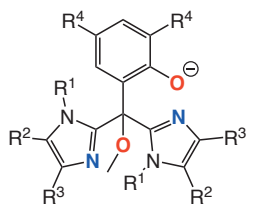

Phenolate 


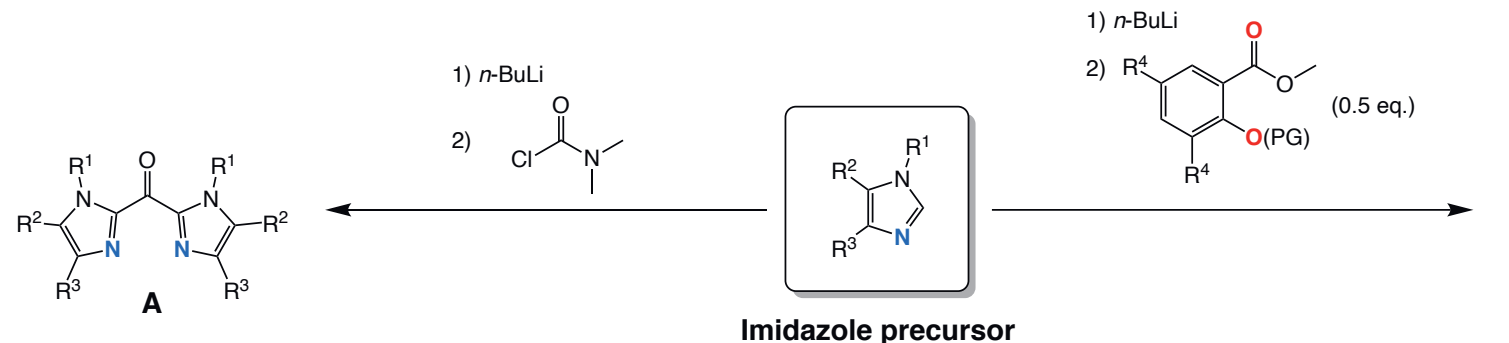

Imidazole precursor<smiles>[Y][C@H](O)OO</smiles><smiles>[R]c1nc(Cc2nc([2H])c([R])[nH]2)[nH]c1[2H]</smiles><smiles>CCOC(=O)CC(=O)OCC</smiles><smiles>CNc1ccccc1N</smiles>

C

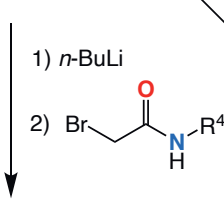

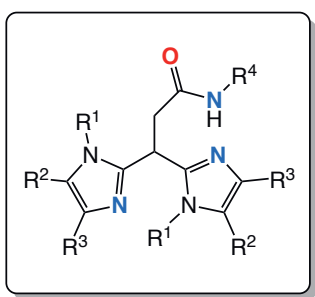

Amide
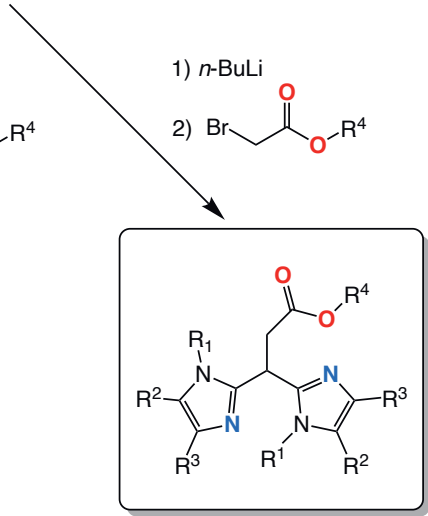

Ester

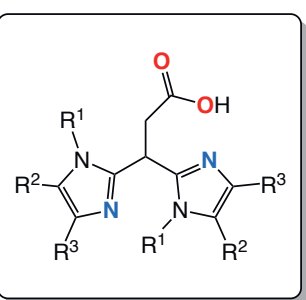

Carboxylic acid

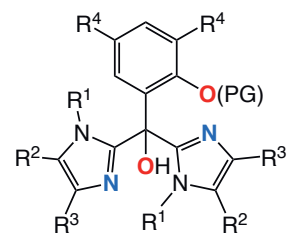

D

1) $\mathrm{NaH}$

$\checkmark$<smiles>[R]OC(c1cc([Z7])cc([R7])c1OCCO)(c1nc([R])c([R])n1[R7])c1nc([R])c([R])n1[R]</smiles>

E

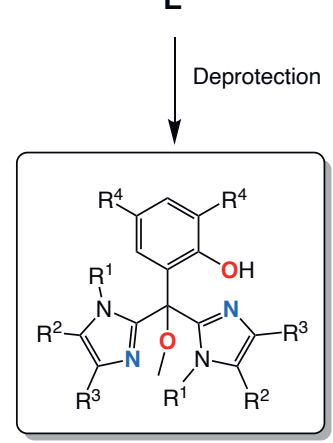

Phenol

Fig. 5. Synthesis map of different imidazole-derived N,N,O ligands in the Klein Gebbink group.

anionic $O$-donor of the $2 \mathrm{H} 1 \mathrm{C}$. The BAIP ligands exist for a range of different substituted imidazoles, including the 1-methylimidazole (L1), 1-methylbenzimidazole (L2), 1-ethyl-4-isopropylimidazole (L3), 1,4-dimethylbenzimidazole (L4), 1-methyl-4,5-diphenylimidazole (L5) (Fig. 6).

Depending on the choice of base, the counter-cation associated to the propionate salt $\left(e . g . \mathrm{Na}, \mathrm{K}\right.$ or $\left.\mathrm{Bu}_{4} \mathrm{~N}\right)$ can be varied. Reaction of the propionate ligand salt with one equivalent of a transition metal salt (e.g. a divalent metal chloride), generally results in the formation of two new salts: the desired metal complex and an (inorganic) by-product (e.g. $\mathrm{KCl}$ ). Choosing the appropriate counter-cation can therefore have an important role in determining the solubility properties of the metal complex and the by-product. In this respect, the choice of solvent also has an important role in determining how easily (inorganic) by-products are eliminated from the reaction mixture and the manner in which the metal complex is extracted or isolated. In our group, the coordination chemistry of the BAIP carboxylate ligand series has been explored with the biologically relevant metals $\mathrm{Fe}, \mathrm{Cu}$ and $\mathrm{Zn}$. The principal results of these studies will be summarised here.

The facial capping potential of $\mathbf{L} \mathbf{1}$ and $\mathbf{L} \mathbf{2}$ was first demonstrated in the work of Bruijnincx et al. ${ }^{[49]}$ where the coordination chemistry of these ligands was explored with copper. Reacting two equivalents of $\mathrm{K}[\mathbf{L 1}]$ or $\mathrm{K}[\mathbf{L 2}]$ with $\mathrm{CuCl}_{2} \cdot 2 \mathrm{H}_{2} \mathrm{O}$ in hot ethanol afforded complexes $\mathbf{1}$ and $\mathbf{2}$, of the type $\left[\mathrm{Cu}^{\mathrm{II}}(\mathrm{L})_{2}\right]$ (Fig. 7). In these complexes, two ligand molecules coordinate by means of the desired anionic $N, N, O$ facial triad, and are arranged in a centrosymmetric manner such that the carboxylate groups occupy mutually trans sites. The complexes both have a distorted octahedral geometry, where the four $\mathrm{Cu}-\mathrm{N}$ bonds occupy the equatorial plane and the two $\mathrm{Cu}-\mathrm{O}$ bonds in the axial positions are elongated slightly (2.4004(17) $\AA$ in 1 and 2.3475(14) $\AA$ in 2) due to the Jahn-Teller distortion. Solid state and frozen solution EPR spectroscopy of $\mathbf{1}$ and $\mathbf{2}$ produced $g_{\|}$and $g_{\perp}$ values typical for an axially elongated geometry.<smiles>Cn1ccnc1C(CC(=O)[O-])c1nccn1C</smiles><smiles>Cn1c(C(CC(=O)[O-])c2nc3ccccc3n2C)nc2ccccc21</smiles>

L1

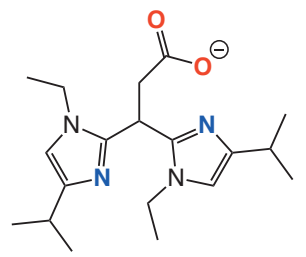

L3

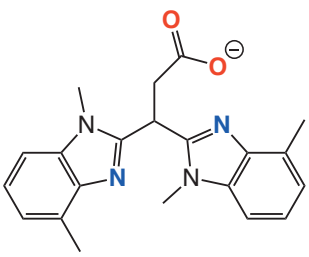

L4

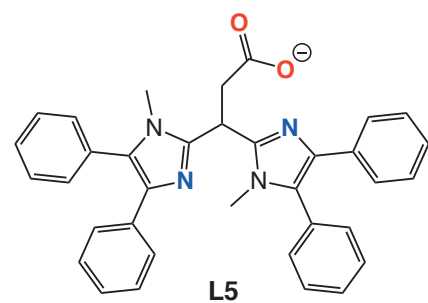

Fig. 6. BAIP-derived $N, N, O$ carboxylate ligands. 
In another study, ${ }^{[48]}$ similar zinc complexes of the type $\left[\mathrm{Zn}^{\mathrm{II}}(\mathrm{L})_{2}\right]$ (4 and 5) were obtained by reacting $\mathbf{L 1}$ or $\mathbf{L 3}$ in a $2: 1$ stoichiometry with $\mathrm{ZnCl}_{2}$ in methanol (Fig. 7, top). The binding modes of the ligands were established by means of ${ }^{1} \mathrm{H}$ NMR and IR spectroscopy. Whereas the ${ }^{1} \mathrm{H}$ NMR analysis for $\mathbf{4}$ was consistent with the structure of a centrosymmetric, bisligated complex, the ${ }^{1} \mathrm{H}$ NMR spectrum of $\mathbf{5}$ revealed two different sets of signals for the ligand's constituent imidazole groups. Supported by DFT, 5 was therefore proposed as being a bisligated zinc complex of tetrahedral geometry, where both ligand molecules adopt an alternative bidentate $N, O$ coordination mode, involving a non-coordinated imidazole group. This is believed to derive from the larger steric component provided by the iso-propyl groups, which do not accommodate $\kappa_{3}-N, N, O$ coordination of two $\mathbf{L 3}$ equivalents simultaneously to a single metal ion.

The reaction of $\mathrm{K}[\mathbf{L 1}]$ with half an equivalent of $\mathrm{Fe}(\mathrm{OTf})_{2} \cdot 2 \mathrm{MeCN}$ in methanol afforded complex 3, which was assigned as being analogous in structure to $\mathbf{1}$ and $\mathbf{4}$ by means of ESI-MS and IR spectroscopy as well as elemental analysis (Fig. 7, top). ${ }^{[51]}$ The structure was later confirmed by X-ray crystallography by Holland and co-workers. ${ }^{[53]}$ Preliminary catalytic studies of $\mathbf{3}$ in alkane and alkene oxidations using $\mathrm{H}_{2} \mathrm{O}_{2}$ as an oxidant showed that $\mathbf{3}$ is ineffective as a catalyst for these kinds of transformations. This was attributed to the relatively strong interaction between the two monoanionic ligands and the metal ion, resulting in a low rate of ligand exchange and higher degree of coordinative saturation in solution, which reduces the interaction between the metal and the oxidant.

Independently, at approximately the same period, the Burlzaff group reported the synthesis of manganese and rhenium carbonyl complexes of the type $\left[\mathrm{M}^{\mathrm{I}}(\mathbf{L 1})(\mathrm{CO})_{3}\right](\mathbf{6}$ and 7$)$, where facial $N, N, O$ coordination of a single equivalent of $\mathbf{L} \mathbf{1}$ was achieved due to the strongly-coordinating nature of the carbonyl ligands that dissuaded the coordination of a second equivalent of supporting ligand. ${ }^{[52]}$ Using this knowledge, the strategy towards monoligated complexes in our group was adapted to include the addition of a biologically relevant co-ligand (e.g. a catecholate), such that the coordination sites trans to the facial $N, N, O$ supporting ligand would no longer be available for the formation of bisligated $\left[\mathrm{M}(\mathrm{L})_{2}\right]$-type complexes.

In an important study by Bruijnincx et al., novel non-heme iron catecholato complexes were developed that are able to successfully model, both structurally and functionally, the active site of extradiol cleaving catechol dioxygenases. ${ }^{[54]}$ A series of high spin $(S=2)$ ferrous complexes of the type $\left[\mathrm{Fe}^{\mathrm{II}}(\mathrm{L})(\mathrm{Htcc})\right](\mathbf{8}-\mathbf{1 0})$ were synthesised by combining equimolar amounts of $\mathrm{K}[\mathrm{L}](\mathrm{L}=\mathbf{L} 1, \mathbf{L 2}, \mathbf{L 3})$ and $\mathrm{Fe}(\mathrm{OTf})_{2} \cdot 2 \mathrm{MeCN}$ in methanol with a methanolic solution of equimolar amounts of tetrachlorocatechol $\left(\mathrm{H}_{2} \mathrm{tcc}\right)$ and $\mathrm{Et}_{3} \mathrm{~N}$ (Fig. 8).
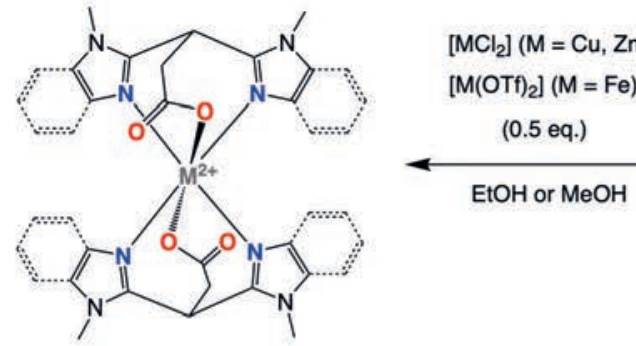

$\left[\mathrm{Cu}(\mathbf{L} 1)_{2}\right](\mathbf{1})$

$\left[\mathrm{Cu}(\mathbf{L 2})_{2}\right](\mathbf{2})$

$\left[\mathrm{Fe}(\mathbf{L} 1)_{2}\right](3)$

$\left[\mathrm{Zn}(\mathbf{L} 1)_{2}\right](\mathbf{4})$

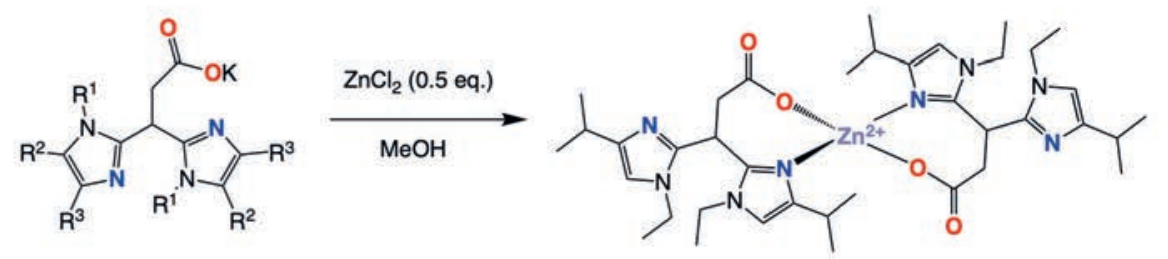

$K[L] \quad(L=L 1, L 2, L 3)$ $\left[\mathrm{MBr}(\mathrm{CO})_{5}\right]$ (1 eq.) ( $\mathrm{M}=\mathrm{Re}, \mathrm{Mn})$<smiles>Cn1ccnc1C(=O)OC(=O)[N+](C(=O)[O-])(C(=O)[O-])C(=O)O</smiles>

$\left[\operatorname{Re}(\mathrm{L1})(\mathrm{CO})_{3}\right](6)$ $\left[\mathrm{Mn}(\mathrm{L1})(\mathrm{CO})_{3}\right](\mathbf{7})$

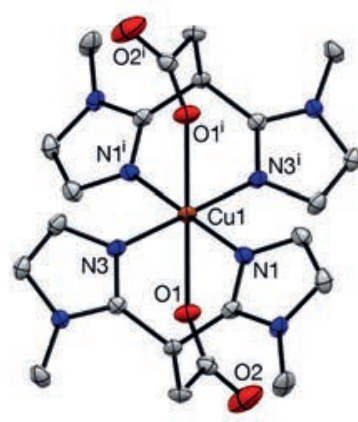

1

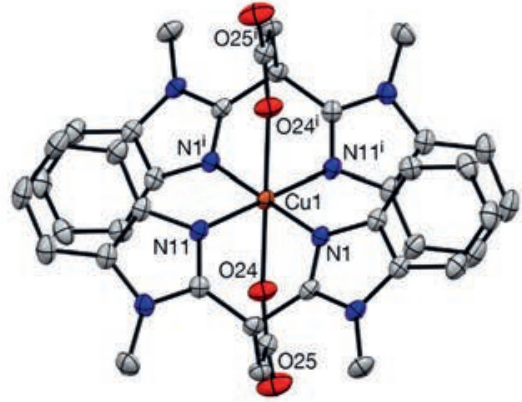

2

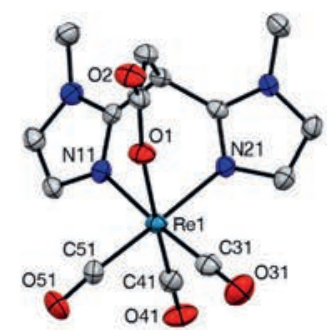

6

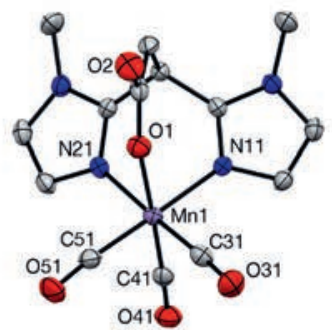

7

Fig. 7: The synthesis of $1-4,{ }^{[49-51]}$ as well as $\mathbf{5}$ and $\mathbf{6} .^{[52]}$ The crystal structures of $\mathbf{1}, \mathbf{2}, \mathbf{5}$ and $\mathbf{6}$ are also provided, where all $\mathrm{H}$-atoms have been omitted for clarity and displacement ellipsoids are drawn at the $50 \%$ probability level. ${ }^{[49-51]}$ 
On the basis of ESI-MS and elemental analysis, the complexes were proposed as being neutral, pentacoordinate, complexes featuring the desired anionic $N, N, O$ coordination of the supporting ligand and the bidentate monoanionic coordination of the catechol. Analogous reactions using 3,5-di-tert-butylcatechol $\left(\mathrm{H}_{2} \mathrm{dtbc}\right)$ afforded complexes $\left[\mathrm{Fe}^{\mathrm{II}}(\mathrm{L})(\mathrm{Hdtbc})\right](\mathbf{1 1 - 1 3})$ that were so air-sensitive that they could not be isolated, and were therefore generated in situ. Corresponding high spin $(\mathrm{S}=5 / 2)$ ferric complexes $\left[\mathrm{Fe}^{\mathrm{III}}(\mathrm{L})(\mathrm{tcc})\right]$ (14-16) and $\left[\mathrm{Fe}^{\mathrm{III}}(\mathrm{L})(\mathrm{dtbc})\right](\mathbf{1 7}-\mathbf{1 9})$ were synthesised by reacting equimolar amounts of $\mathrm{K}[\mathrm{L}](\mathrm{L}=\mathbf{L} \mathbf{1}, \mathbf{L} 2, \mathbf{L 3})$ and $\mathrm{Fe}\left(\mathrm{NO}_{3}\right)_{3} \cdot 9 \mathrm{H}_{2} \mathrm{O}$ in methanol with a methanolic solution of the desired catechol and two equivalents of $\mathrm{Et}_{3} \mathrm{~N}$ (Fig. 8). The crystal structure of $\mathbf{1 6}$ was obtained, revealing the desired $N, N, O$ coordination of $\mathbf{L 3}$, as well as the bidentate dianionic coordination of tcc to the $\mathrm{Fe}^{3+}$ ion. An additional water molecule was observed to bind to the sixth available coordination site, completing the distorted octahedral geometry of the complex. This coordination site can be regarded as a potential site for direct coordination of dioxygen to the metal centre, $c i s$ to the catecholate co-ligand and trans to one of the imidazole heterocycles. Overall, these complexes are some of the most accurate structural models of extradiol-cleaving catechol oxygenase enzymes to date. seen to be strongly dependent on the solvent of choice. Strongly coordinating solvents such as acetonitrile or methanol can bind to the vacant site and are therefore hypothesised to inhibit the binding of dioxygen, thereby resulting predominantly in the formation of the auto-oxidation product, 3,5-di-tert-butylbenzoquinone (Fig. 9). In non-coordinating solvents such as dichloromethane, the vacant site becomes available for dioxygen binding and, consequently, the product distribution was observed to change dramatically. Although a portion of the catechol was still observed to auto-oxidise to the quinone (approx. 45\%), a considerable amount of intra- and extradiol cleavage products was also observed, accounting for about $30 \%$ of the organic products each. The selectivity for extradiol cleavage was seen to improve upon addition of a proton donor, such as $\left[\mathrm{Et}_{3} \mathrm{NH}\right] \mathrm{BF}_{4}$. The ability of 11-13 to mediate both extradiol and intradiol cleavage reactivity is quite exceptional, and suggests that the two reaction pathways may share a common intermediate. This supports the hypothesis that extradiol cleaving catechol dioxygenases derive their selectivity from factors beyond the primary coordination sphere of the enzyme active site.

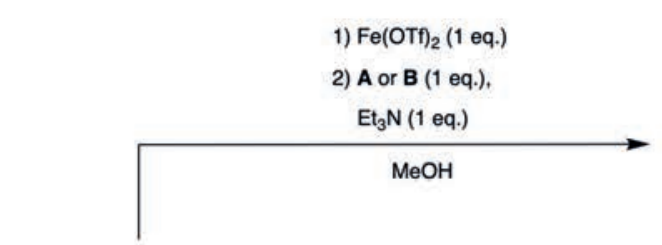<smiles>[R]c1nc(C(CC(=O)OC)c2nc([2H])c([2H])[nH]2)[nH]c1[2H]</smiles>

$K[L] \quad(L=L 1, L 2, L 3)$

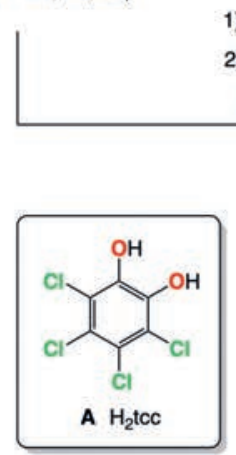

1) $\mathrm{Fe}\left(\mathrm{NO}_{3}\right)_{3}$ (1 eq.)

2) $A$ or $B$ (1 eq.).

$\mathrm{Et}_{3} \mathrm{~N}$ (2 eq.)

$\mathrm{MeOH}$

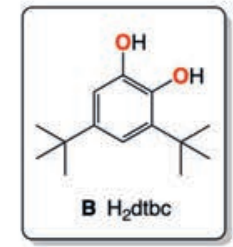

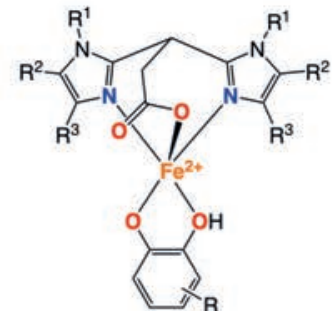

$[\mathrm{Fe}(\mathrm{L} \mathbf{1})(\mathrm{Htcc})](\mathbf{8}) \quad[\mathrm{Fe}(\mathrm{L} \mathbf{1})(\mathrm{Hdtbc})](\mathbf{1 1})$

$[\mathrm{Fe}(\mathrm{L2})(\mathrm{Htcc})](9) \quad[\mathrm{Fe}(\mathrm{L2})(\mathrm{Hdtbc})](12)$

$[\mathrm{Fe}(\mathrm{L} 3)(\mathrm{Htcc})](10) \quad[\mathrm{Fe}(\mathrm{L} 3)(\mathrm{Hdtbc})](13)$

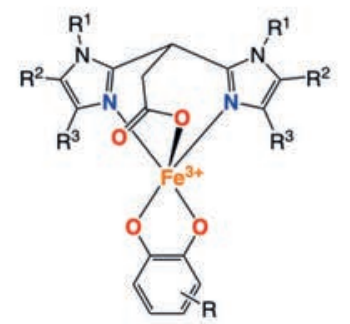

$[\mathrm{Fe}(\mathrm{L} 1)(\mathrm{tcc})](\mathbf{1 4}) \quad[\mathrm{Fe}(\mathrm{L} 1)(\mathrm{dtbc})](\mathbf{1 7})$ $[\mathrm{Fe}(\mathbf{L} 2)(\mathrm{tcc})](\mathbf{1 5}) \quad[\mathrm{Fe}(\mathbf{L 2})(\mathrm{dtbc})](18)$ $[\mathrm{Fe}(\mathrm{L3})(\mathrm{tcc})](16) \quad[\mathrm{Fe}(\mathrm{L} 3)(\mathrm{dtbc})](19)$

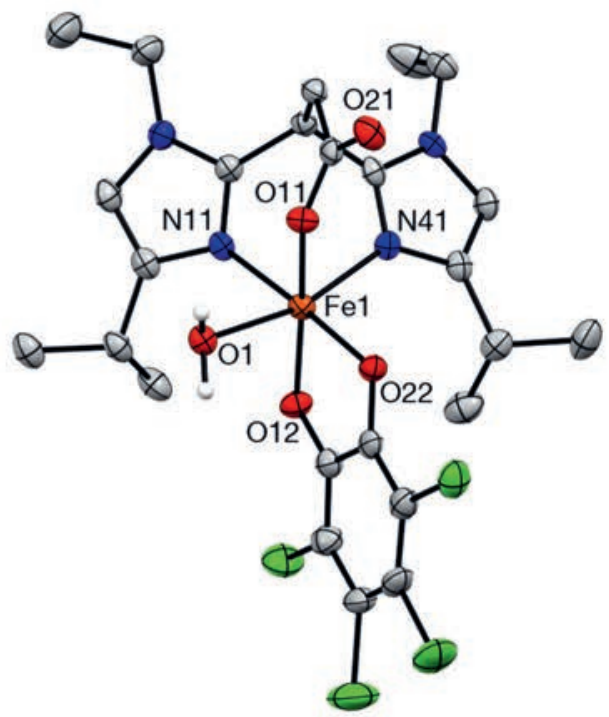

16. $\mathrm{H}_{2} \mathrm{O}$

Fig. 8. Synthesis of non-heme iron(II) and iron(III) catecholate complexes (8-19), supported by $\mathbf{L} \mathbf{1}$, L2 and $\mathbf{L} 3$. The crystal structure of $\mathbf{1 6} \cdot \mathrm{H}_{2} \mathrm{O}$ is also provided, where all $\mathrm{C}-\mathrm{H}$ hydrogen atoms have been omitted for clarity and displacement ellipsoids are drawn at the $50 \%$ probability level. ${ }^{[54]}$

Exposing methanolic solutions of complexes 11-13 to air resulted in a rapid colour change from pale yellow-brown to blue-purple. In the electronic absorption spectra, new bands were seen to develop at around 324, 490 and $800 \mathrm{~nm}$, characteristic for catecholato-to-iron(III) LMCT bands and identical to those observed for the independently synthesised complexes 17-19. [42] The first oxidative transformation was therefore ascribed to a one-electron redox oxidation of the ferrous complexes to their ferric counterparts. This was followed by a much slower colour change from blue-purple to green, ascribed to the oxidative degradation of the complexes as the catechol converted to products of ring-cleavage reactivity and auto-oxidation. The resulting product distribution isolated from the air-exposed reaction mixtures was
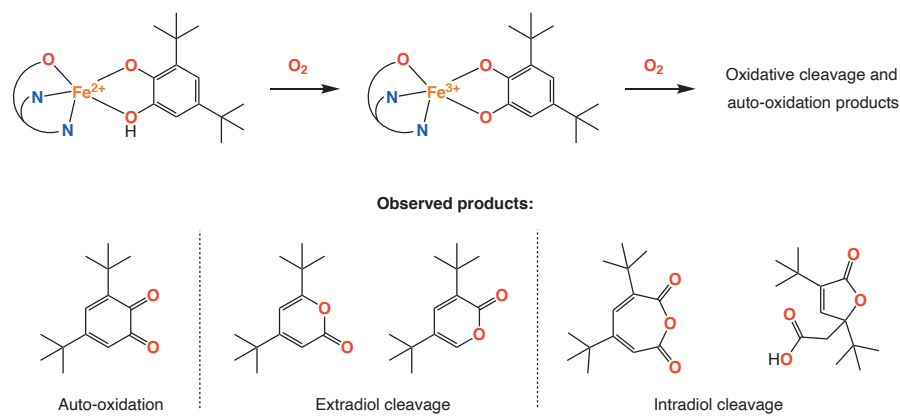

Fig. 9. The dioxygen reactivity of complexes 11-13. Figure adapted from Bruijnincx et al. ${ }^{[54]}$ 
One of the disadvantages associated with the BAIP carboxylate ligand series is the tendency for the carboxylate group to engage in alternative, bridging coordination modes. This was first observed by Bruijnincx et al. in an attempt to synthesise monoligated zinc complexes. ${ }^{[50]}$ Reacting $\mathrm{K}[\mathbf{L 1}]$ or $\mathrm{K}[\mathbf{L} 3]$ with an equimolar amount of $\mathrm{ZnCl}_{2}$ in methanol afforded complexes 20 and 21, respectively, which were identified as having the desired composition, $\left[\mathrm{Zn}^{\mathrm{II}}(\mathrm{L})(\mathrm{Cl})\right]$, but which was identified by means of ESI-MS, NMR, IR and X-ray crystallography as being oligomeric in structure (Fig. 10). In each complex, the zinc ion is coordinated by the bidentate bis-imidazole moiety of one ligand molecule and the monodentate carboxylate group of a neighbouring ligand molecule. Each zinc ion is bound to a chloride ligand, and an additional water ligand is observed in $\mathbf{2 0 .}$ ordination sphere. Small ligands such as $\mathbf{L} \mathbf{1}$ and $\mathbf{L} \mathbf{2}$ are capable of forming bisligated complexes, where both ligand molecules coordinate by means of a tridentate $\kappa_{3}-N, N, O$ coordination mode. In contrast, the sterically more demanding $\mathbf{L} \mathbf{3}$ can only bisligate by chelating in a bidentate $\kappa_{2}-N, O$ fashion. The second factor is the propensity for carboxylate ligands to bridge when, for example, there is no co-ligand available to complete the coordination sphere of the metal ion. In these cases, the carboxylate ligands may compete to fill these vacant sites. For catalytic applications, it is desirable to avoid the formation of bisligated complexes and complexes featuring alternative ligand coordination modes. These complexes do not model the $2 \mathrm{H} 1 \mathrm{C}$ to a high degree of accuracy, and may therefore be considered off-cycle species that could lead to loss of catalyst selectivity or even catalyst de-acti-

Fig. 10. Synthesis of oligomeric zinc complexes 20 and $\mathbf{2 1}$. Individual crystallographic monomers of $\mathbf{2 0}$ and $\mathbf{2 1}$ are also provided. ${ }^{[50]}$

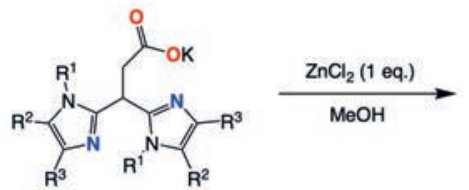

$K[L] \quad(L=L 1, L 3)$

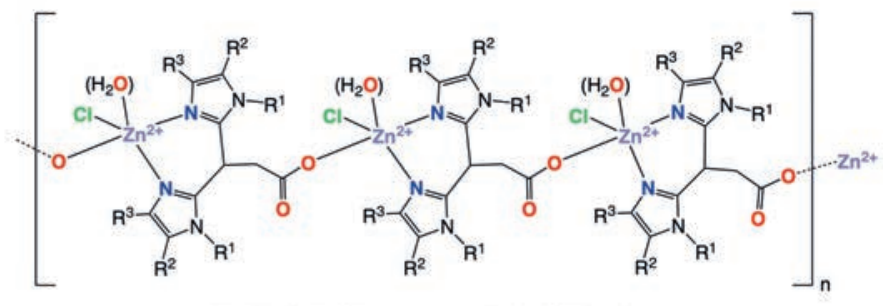

$\left[\mathrm{Zn}(\mathrm{L1})(\mathrm{Cl})\left(\mathrm{H}_{2} \mathrm{O}\right)\right]_{n}(20) \quad[\mathrm{Zn}(\mathrm{L3})(\mathrm{Cl})]_{n}(21)$

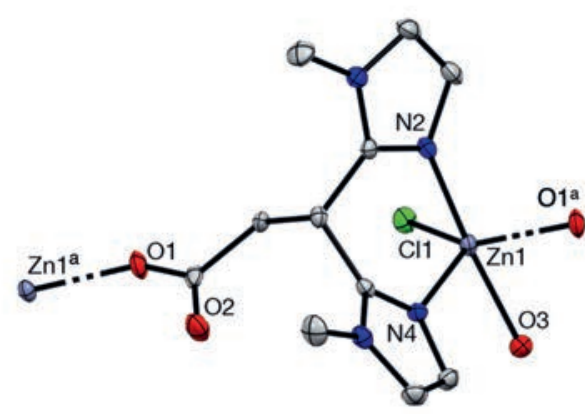

20

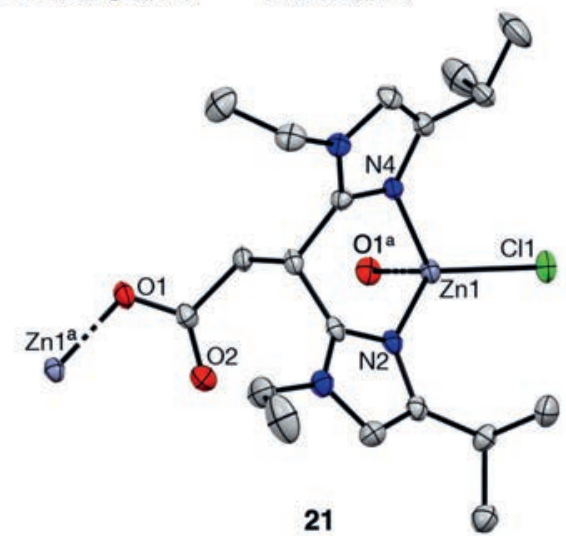

21
Bridging coordination modes of the carboxylate group were also observed in the pentanuclear iron cluster complex, $\left[\mathrm{Fe}_{5}(\mathbf{L 5})_{4}(\mathrm{~F})_{4}\right]\left(\mathrm{BF}_{4}\right)_{2}(\mathbf{2 2})$, obtained from the reaction of $\mathrm{K}[\mathbf{L 5}]$ with $\mathrm{Fe}\left(\mathrm{BF}_{4}\right)_{2} \cdot 6 \mathrm{H}_{2} \mathrm{O}$ in 1:1 stoichiometry (Fig. 11). ${ }^{[55]}$ The structure consists of a centrosymmetric cluster containing a total of five iron nuclei of distorted octahedral geometry. Each ligand molecule binds in a $\kappa_{3}-N, N, O$ fashion to a single iron nucleus, although all ligands further engage in additional bridging carboxylate coordination modes to one or two neighbouring iron atoms. Two of the ligand molecules bridge to one other iron centre by means of one of their carboxylate oxygen atoms $\left(\mu_{2}: \kappa_{1}\right.$-carboxylate, $\left.\mathbf{A}\right)$, whereas the two other ligand molecules bridge to two other iron centres using both of their carboxylate oxygen atoms $\left(\mu_{3}: \kappa_{2}\right.$-carboxylate, B). The fifth iron nucleus is located on the cluster's centre of inversion, bound by four fluoride ions on the equatorial positions and the two $\mu_{3}: \kappa_{2}$-carboxylate groups on the axial positions. Although 22 is the product of a tetrafluoroborate anion degradation pathway, this complex nonetheless demonstrates nicely the multiple different coordination modes with which BAIP carboxylate ligands can interact with metal ions.

In conclusion, it is evident that the coordination chemistry exhibited by BAIP carboxylate ligands is overall rich and diverse, but it can be difficult to control. It is governed by two important factors. The first is the steric bulk of the imidazole heterocycle. This determines the ease with which a second ligand equivalent can coordinate on the opposite face of the metal's co-

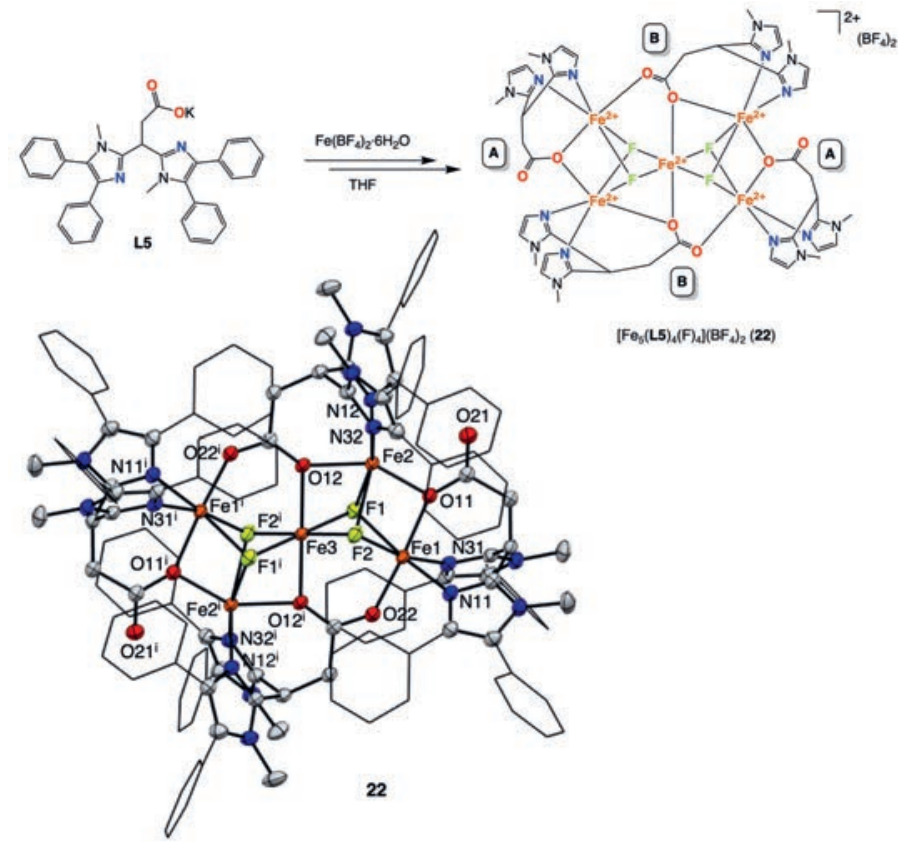

Fig. 11. Synthesis of the pentanuclear iron complex 22. ${ }^{[55]}$ Phenyl groups on the imidazole groups are not drawn for clarity. The crystal structure of 22 is also provided, ${ }^{[56]}$ with $\mathrm{BF}_{4}$ ions omitted for clarity. Phenyl substituents are depicted in the wireframe format for clarity. 
vation. Overall, the most promising tactic toward a desired facial, tridentate $N, N, O$ mode from a BAIP carboxylate ligand has been the use of co-ligands, such as mono- or dianionic catecholate ligands. The use of various co-ligands also provides opportunities to mimic a myriad of different members of the mononuclear non-heme enzyme superfamily, each of which has its own specific coordination chemistry. Other strategies have involved a modification of the nature of the ligand itself, to an ester, an amide or a phenolate.

\subsection{Ester Ligands}

As was the case for their carboxylate analogues, the BAIP ester ligands can be modulated by changing the nature of the imidazole heterocycle. However, the organic substituent on the ester itself can also be tuned easily (e.g. to an $n$-propyl or tert-butyl substituent). The BAIP-derived ester family of ligands is depicted in Fig. 12. Changing a carboxylate group into an ester functionality also has significant consequences for the electronic properties of the ligand. Most importantly, the neutral configuration of the ester prohibits the ligand from coordinating in an anionic fashion. In many cases, counter-anions are present in the metal complexes formed, as they have the role of balancing the positive charge of the metal ion to which the ligand is bound. Depending on the nature of these counter-cations, the coordination chemistry of the ester ligands changes significantly.
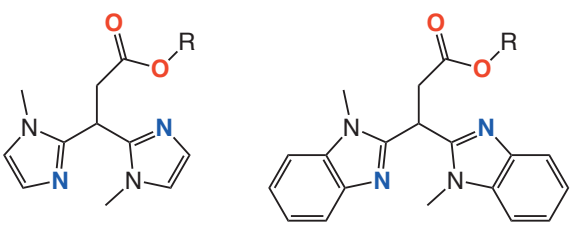

$\mathrm{L}^{\mathrm{nPr}} \mathrm{R}=n-\mathrm{Pr}$

$\mathrm{L}^{\mathrm{nPr}} \quad \mathrm{R}=n-\mathrm{Pr}$

$\mathrm{L}^{\mathrm{tBu}} \quad \mathrm{R}=t-\mathrm{Bu}$

$\mathrm{L}^{\mathrm{tBu}} \mathrm{R}=t-\mathrm{Bu}$

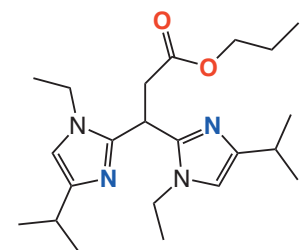

L3 $^{\text {nPr }}$
The analogous reaction between two equivalents of $\mathbf{L 3}^{\text {nPr }}$ and $\mathrm{Fe}(\mathrm{OTf})_{2} \cdot 2 \mathrm{MeCN}(2: 1)$ also afforded a product identified as a bisligated complex, $\left[\mathrm{Fe}\left(\mathbf{L 3}^{\text {nPr }}\right)_{2}\right](\mathrm{OTf})_{2}(\mathbf{2 7})$, although the presence of three different IR stretches, assigned to cis, trans and non-coordinating binding modes of the ester ligand, were an indication that the complex exists as several different isomers. This was confirmed by the X-ray crystal structure, where isomeric octahedral (27a) and tetrahedral (27b) complexes were observed within the same unit cell in a 1:2 ratio (Fig. 14). In 27a, the ligands coordinate with a facial, tridentate $N, N, O$ binding motif and their two carbonyl groups are orientated cis with respect to each other. In $\mathbf{2 7} \mathbf{b}$, two ligand molecules bind the iron centre in bidentate $N, N$ fashion, where the ester moiety remains unbound. These results demonstrate nicely the coordinative lability of the neutral ester functionality in $\mathbf{L 3}^{\mathbf{n P r}}$ that arises from the relatively weak interaction between the metal and the carbonyl group. However, this also indicates that off-cycle species may easily form during catalytic applications of ester-bound complexes, which could lead to potential catalyst degradation or inactivation.

Catalysis experiments showed that $\mathbf{2 3}$ is an active catalyst for the epoxidation and cis-dihydroxylation of various olefins, including cyclo-octene, styrene, 1-octene, cyclo-hexene, trans2-heptene and cis-2-heptene, for a catalyst/oxidant/substrate ratio of 1:10:1000, with $\mathrm{H}_{2} \mathrm{O}_{2}$ conversion efficiencies ranging

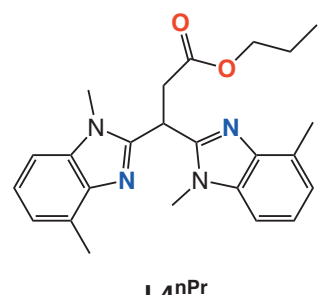

$\mathrm{L} 4^{\mathrm{nPr}}$

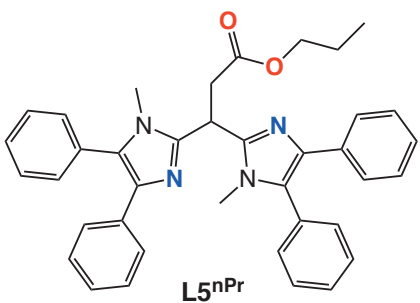

Fig. 12. BAIP-derived N,N,O ester ligands.

The potential for the $\mathbf{L} \mathbf{1}^{\mathbf{R}}$ and $\mathbf{L} \mathbf{2}^{\mathbf{R}}\left(\mathrm{R}={ }^{n} \mathrm{Pr},{ }^{t} \mathrm{Bu}\right)$ ester ligands to coordinate in a facial $N, N, O$ manner was demonstrated in two separate studies, by Bruijnincx and Moelands. ${ }^{[51,57]}$ Reacting the ligand with the $\mathrm{Fe}(\mathrm{OTf}) \cdot 2 \mathrm{MeCN}$ in 2:1 stoichiometry afforded high spin $(S=2)$ complexes of the type $\left[\mathrm{Fe}^{\mathrm{II}}(\mathrm{L})_{2}\right](\mathrm{OTf})_{2}(\mathbf{2 3}, \mathbf{2 4}$, Fig. 13). From the crystal structures, the ester ligands in all complexes were observed to coordinate by means of a tridentate $\mathrm{N}, \mathrm{N}, \mathrm{O}$ binding motif, comprising the two imidazole $N$-donors and the carbonyl oxygen atom of the ester functionality. All complexes were observed to have distorted octahedral geometries, although some differences could be seen in the manner with which the ligands wrapped themselves around the metal centre. In complexes 23, 24 and 26, the ligands coordinate trans with respect to each other, meaning that the four $N$-donors occupy the equatorial positions and the $O$-donors occupy the axial positions. However, the $\mathbf{L} 2^{\text {nPr }}$ ligands in $\mathbf{2 5}$ are bound such that the $O$-donors coordinate $c i s$ with respect to each other. Although this was tentatively proposed as arising from the lesser steric clash of the $n$-propyl esters compared to that of tert-butyl group, it cannot be excluded that the cis isomer of $\mathbf{2 5}$ may simply crystallise more easily from solution than the trans isomer. Overall, these complexes demonstrate once again the ease with which the $\mathbf{L} \mathbf{1}$ and $\mathbf{L} 2$ bis-benzimidazole backbones can accommodate the $\kappa_{3}$ $N, N, O$ coordination of two ligand molecules simultaneously to the metal centre. Furthermore, it demonstrates the relatively small impact that the ester's organic substituents has on the coordination geometry about the metal centre. Due to the coordination of the ester's carbonyl oxygen atom to the metal centre, the organic substituents in fact orientate away from the metal centre rather than towards it. from $39-51 \% .{ }^{[51]}$ While the reaction with 1-octene produced the cis-diol product in almost 2:1 ratio with respect to the epoxide, reactions with the other substrates showed preferential selectivity for the epoxidation product. To date, only few non-heme iron catalysts featuring a tridentate $N, N, O$ ligand are capable of catalysing both epoxidation and cis-dihydroxylation. Testing 24-27 as catalysts for the oxidation of cyclo-octene resulted in comparable product distributions as that obtained with $\mathbf{2 3}$, although the complexes were observed to be less active than 23. $^{[57]}$ The lability of the ester functionality is thought to play a vital role in catalysis by enabling $c i s$-vacant sites to exist at the high spin iron centre, enabling the oxidant and the substrates to bind directly to the iron in close proximity. It is likely that the larger size of the imidazole substituents in 25-27 reduces the accessibility of the iron centre, thereby reducing the efficacy of catalysis using these complexes.

An important breakthrough was published in a study by Folkertsma et al., which demonstrated that the reaction between $\mathbf{L 4}{ }^{\mathbf{n P r}}$ and $\mathrm{Fe}(\mathrm{OTf})_{2} \cdot 2 \mathrm{MeCN}$ in equimolar amount resulted in the formation of a mononuclear, high spin $(S=2)$ iron complex, $\left[\mathrm{Fe}^{\mathrm{II}}\left(\mathbf{L} \mathbf{4}^{\mathrm{nPr}}\right)(\mathrm{OTf})\right]_{2}(\mathbf{2 8})$, in which the ligand coordinates with the desired facial, $N, N, O$ binding motif, leaving two vacant sites available for the (loose) coordination of the triflate anionic (Fig. 15). ${ }^{[58]}$ This was the first example of a monoligated complex that could form in the absence of a co-ligand. On the basis of DFT calculations, it was proposed that the additional methyl substituent on the 4-position of the benzimidazole ring was responsible for driving the coordination equilibrium towards the thermodynam- 

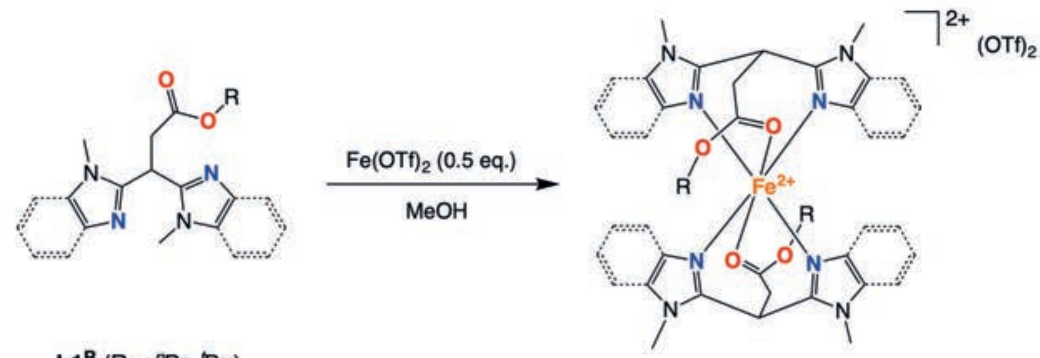

$$
\begin{aligned}
& \mathbf{L 1}^{\mathbf{R}}\left(\mathbf{R}={ }^{n} \mathrm{Pr},{ }^{\mathrm{B} u}\right) \\
& \mathbf{L 2}^{\mathbf{R}}\left(\mathbf{R}={ }^{n} \mathrm{Pr},{ }^{\mathrm{B} u}\right)
\end{aligned}
$$

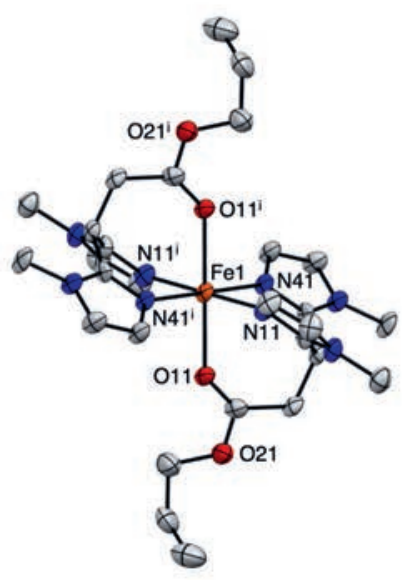

23

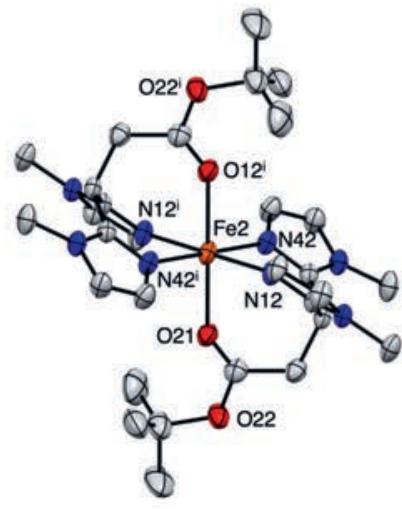

24
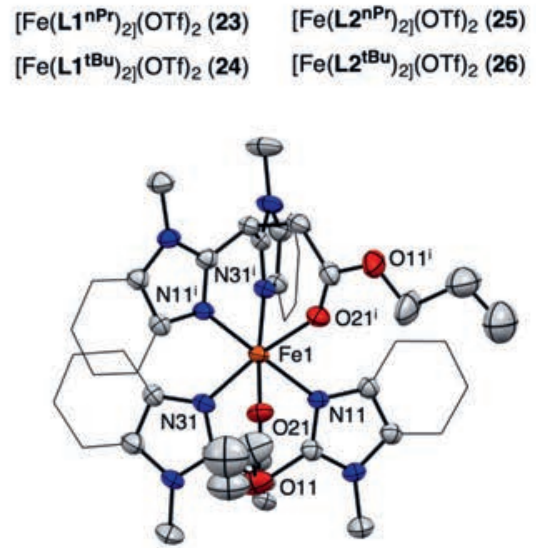

25

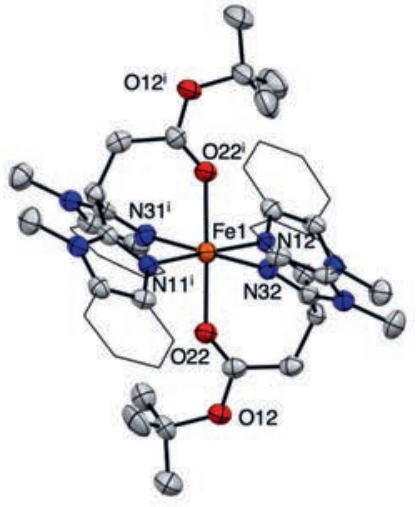

26

Fig. 13. Synthesis of complexes 23-26. ${ }^{[57]}$ Crystal structures of the complexes are also provided, with $\mathrm{H}$-atoms and non-coordinated OTf anions omitted for clarity. Displacement ellipsoids are drawn at the $50 \%$ probability level. Aromatic rings of the benzimidazole substituents have been depicted in the wireframe format for clarity. ${ }^{[57]}$

ically favourable formation of $\mathbf{2 8}$. The pentacoordinate nature of 28, as well as its geometrical parameters in the crystal structure, were observed to model closely the structure of the active site of 2,3-dihydroxybiphenyl dioxygenase (BphC), an extradiol-type ring cleaving dioxygenase. ${ }^{[59]}$ Nonetheless, ${ }^{1} \mathrm{H}$ NMR analysis in $\mathrm{CD}_{3} \mathrm{CN}$ revealed that multiple paramagnetic species were present in solution, indicating that the complex undergoes coordination equilibria in strongly coordinating solvents. Whether this is sim- ply solvent exchange with the triflate anions or lability of the ester functionality was not determined. Carrying out an analogous reaction using equimolar amounts of $\mathbf{L} 4^{\mathbf{n P r}}$ and $\mathrm{FeCl}_{2}$ resulted in the formation of a mononuclear iron complex (29) in which $\mathbf{L} 4^{\mathbf{n P r}}$ binds in bidentate $N, N$ fashion, with a non-coordinating ester functionality. This demonstrates the influence that the strongly coordinating chloride ligands have on promoting the dissociation of the ester moiety.
Fig. 14. Synthesis of the isomeric complexes $27 \mathrm{a}$ and $\mathbf{2 7 b}$, where $\mathbf{L}^{\text {nPr }}$ adopts two different coordination modes. Crystal structures of the complexes are also provided, with $\mathrm{H}$-atoms and OTf anions omitted for clarity. Displacement ellipsoids are drawn at the $50 \%$ probability level. ${ }^{[57]}$
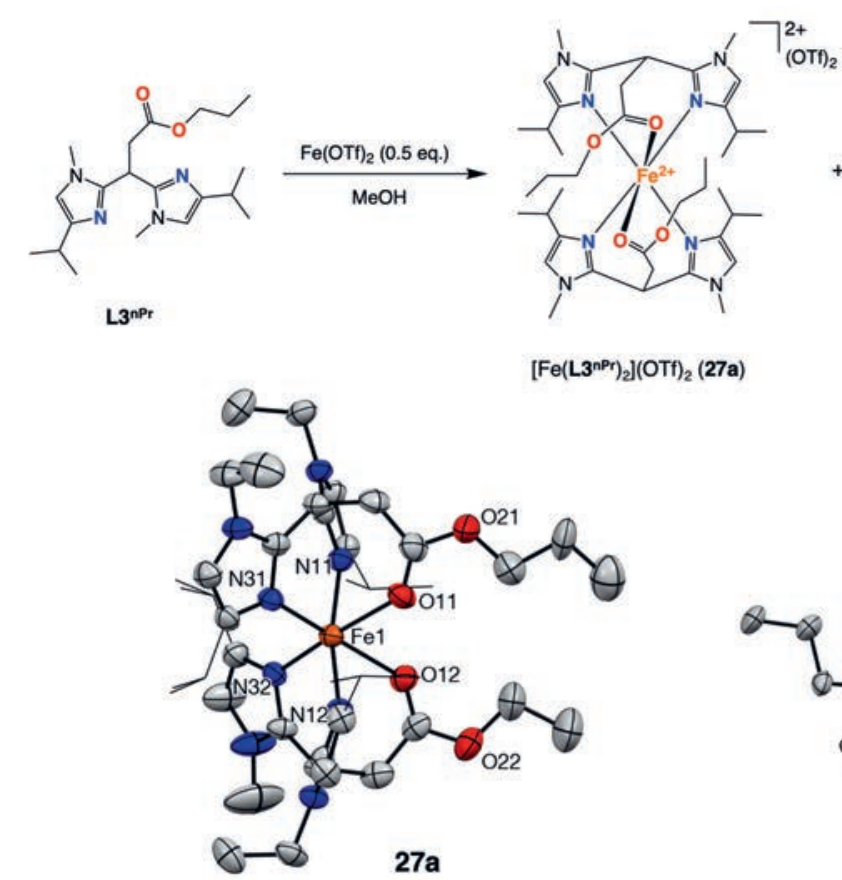

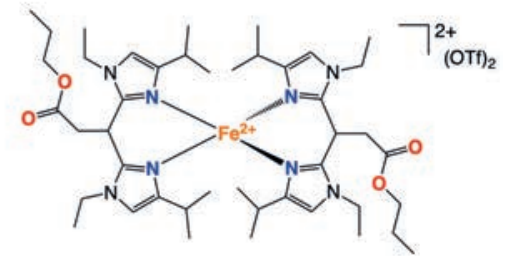

$\left[\mathrm{Fe}\left(\mathrm{K}_{\mathrm{N}, \mathrm{O}}-\mathrm{L} 3^{\mathrm{nPr}}\right)_{2}\right](\mathrm{OTf})_{2}(27 \mathrm{~b})$

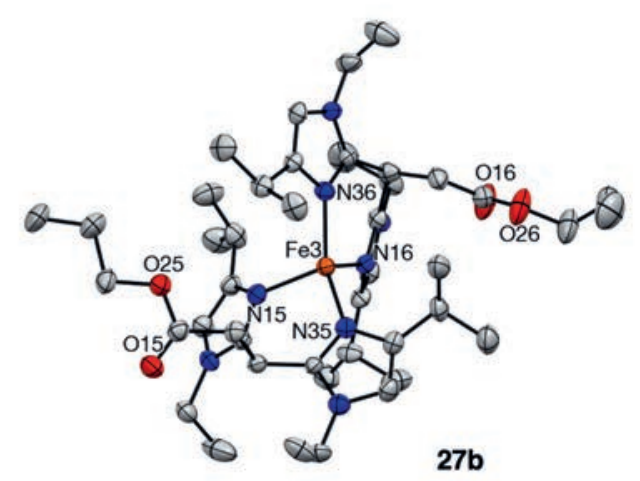




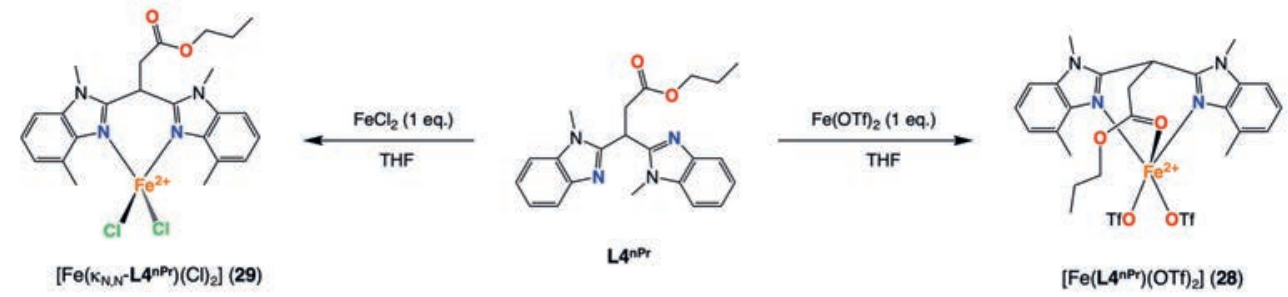

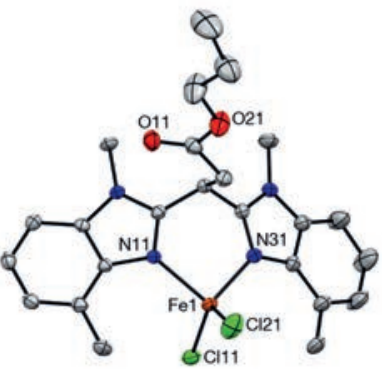

29

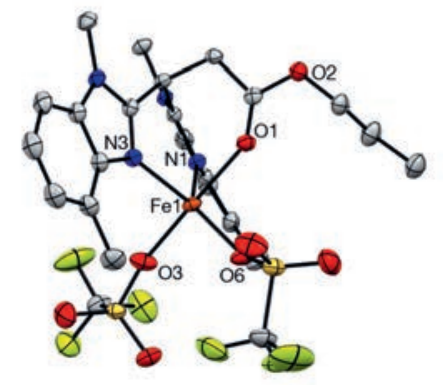

28

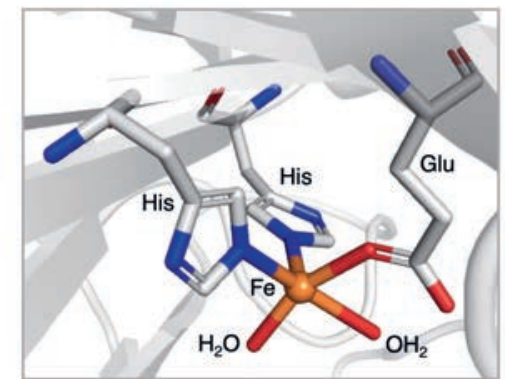

BphC (PDB 1EIL)
Fig. 15. Synthesis of complexes 28 and 29 using L4 ${ }^{\mathrm{PPr}}$. Crystal structures of both complexes are also provided, with $\mathrm{H}$-atoms omitted for clarity and displacement ellipsoids drawn at the $50 \%$ probability level. ${ }^{[58]}$ The crystal structure of the active site of $\mathrm{BphC}$ is provided for comparison. ${ }^{[59]}$
Given these results, $\mathbf{L 5}^{\mathrm{nPr}}$ was developed to incorporate a higher degree of steric bulk on the imidazole heterocycles. ${ }^{[55]}$ Reacting $\mathbf{L 5}^{\text {nPr }}$ with $\mathrm{Fe}(\mathrm{OTf}) \cdot 2 \mathrm{MeCN}$ in 1:1 stoichiometry afforded a mononuclear, high spin $(S=2)$ iron complex, $\left[\mathrm{Fe}^{\mathrm{II}}\left(\mathbf{L 5}^{\mathbf{n P r}}\right)(\mathrm{OTf})\right.$ (THF)](OTf) (30), similar in structure to 28 (Fig. 16). The iron centre is pentacoordinate and trigonal bipyramidal in geometry $(\tau=0.67),{ }^{[60]}$ bound by the tridentate, facial $N, N, O$ arrangement of donor atoms from the supporting ligand, as well as a triflate molecule and a THF molecule, while the second triflate anion remains unbound. The substitutional lability of the triflate anions was subsequently explored using various biorelevant co-ligands, including aminophenol (deprotonated using $\mathrm{Et}_{3} \mathrm{~N}$ ) and sodium pyruvate. Monitoring the reactions with ESI-MS revealed the presence of ions corresponding to the desired $\left[\mathrm{Fe}\left(\mathbf{L 5}^{\mathrm{nPr}}\right)(\mathrm{co}-\mathrm{li}-\right.$ gand) $]^{+}$complexes, however, the predominant species in both cases was observed to be a bisligated complex, $\left[\mathrm{Fe}\left(\mathbf{L 5}^{\mathbf{n P r}}\right)_{2}\right]$. By means of X-ray crystallography, this complex (31) was identified as being tetrahedral in geometry, involving the coordination of two ligand equivalents in bidentate $N, N$ fashion, and very similar in structure to $\mathbf{2 7 b}$. This result reinforces the trend that the BAIP ester ligands tend to show labile coordination of the ester moiety, thereby increasing the number of available coordination sites on the metal centre, which itself could be a driving force for the formation of these kinds of bisligated, homoleptic complexes.

Overall, tuning the design of the BAIP ester ligands has proven to be successful for achieving the formation of monoligated complexes featuring the desired facial, tridentate $N, N, O$ coordination of the bioinspired ligand framework. The factors that influence the coordination of the BAIP ester ligands are the steric properties of the imidazole heterocycles, in particular, the bulk of the organic substituents that point towards the metal centre upon chelation. Coordination of the ester moiety seems to be particularly sensitive to the nature of the counter anions present. Generally, in the presence of triflate ligands, the ester is observed to bind by means of its carbonyl functionality. However, in the presence of chloride ligands, the ester is seen to dissociate from the iron centre. Based on the results obtained so far, coordination of the ester moiety seems not to be dependent on the nature of its tethered organic substituent. Catalytic activity for the bisligated iron complexes containing BAIP ester ligands is dependent on the lability of the ester functionality, which enables the oxidant and substrate to bind directly to the metal centre. However, catalytic activity
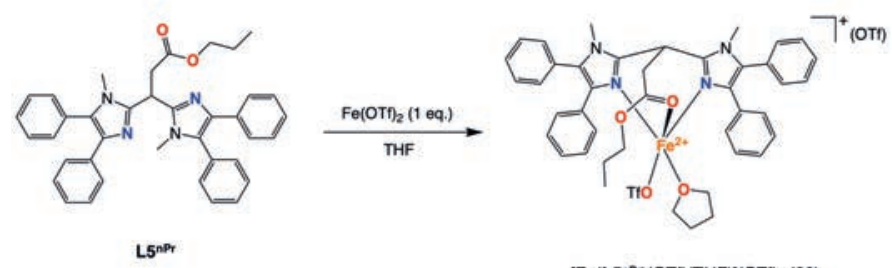

$\left[\mathrm{Fe}\left(\mathrm{LS}^{\mathrm{nP}}\right)(\mathrm{OTf})(\mathrm{THF})\right](\mathrm{OTF})_{2}(30)$

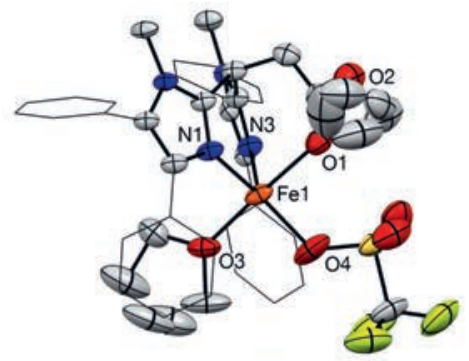

30
Fig. 16. The synthesis of $\mathbf{3 0}$, and the structure of 31. ${ }^{[55]}$ The crystal structures of the complexes are also provided, ${ }^{[61]}$ with $\mathrm{H}$-atoms omitted for clarity and displacement ellipsoids drawn at the $50 \%$ probability level. The phenyl substituents of the imidazole heterocycles have been depicted in the wireframe format for clarity. Disorder is present at some of the $n$-propyl substituents, as well as the THF molecules in $\mathbf{3 0}$. Non-coordinating OTf anions have been omitted for clarity.
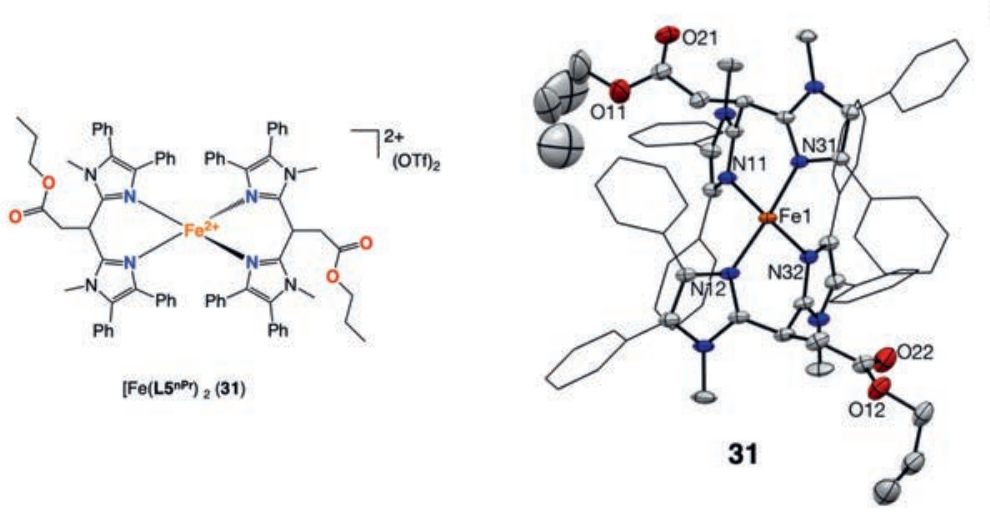
seems to decrease when the size of the imidazole heterocycle increases sufficiently enough to hinder the approach of oxidants or substrates into the coordination sphere of the iron metal.

\subsection{Amide Ligands}

The BAIP ligand family has also been modified to incorporate an amide functionality (Fig. 17). This modification can be regarded as the BAIP-derived sister ligand design to the Ph-DPAH ligand (DPAH $=\operatorname{di}(2$-pyridyl)methylbenzamide) previously reported by the group of Que, which also has an $N, N, O$ donor set. ${ }^{[62]}$ Amides are known to possess two different coordination modes, dependent on the protonation state of the amido nitrogen atom. In their neutral state, amides are most likely to coordinate through their carbonyl oxygen atom, as do the previously described BAIP ester ligands. Alternatively, deprotonation of the amide nitrogen atom could provide an anionic $N$-donor site, whose interaction with a metal atom is predicted to be stronger than that of an analogous carboxylic acid, due to the stronger Lewis acidity of its conjugate base. system, for example, make them unfavourable for further catalysis applications

More recently, attempts were made in our group to achieve anionic coordination modes of the amide ligand $\mathbf{L 4}^{\mathrm{ATol}}$. This ligand was designed to incorporate the bis-1,4-dimethylbenzimidazole ligand scaffold previously reported by Folkertsma et al., ${ }^{[58]}$ whose additional methyl groups were predicted to promote the formation of monoligated complexes. Mixing $\mathbf{L 4}^{\mathrm{ATol}}$ with one equivalent $\mathrm{Fe}(\mathrm{OTf})_{2} \cdot 2 \mathrm{MeCN}$ in $\mathrm{THF}$ resulted in the almost instantaneous precipitation of a white solid, to which one equivalent of $\mathrm{NEt}_{3}$ was added, with the hypothesis that the amide $\mathrm{N}-\mathrm{H}$ bonds would be weakened upon coordination to iron. The resulting product was analysed by ${ }^{1} \mathrm{H}$ NMR spectroscopy, which indicated that a single paramagnetic species was present in solution. Crystal structure determination revealed that a mononuclear, bisligated iron(II) complex had formed, [Fe $\left.{ }^{\mathrm{II}}\left(\mathbf{L 4}^{\mathrm{ATol}}\right)_{2}\right](\mathrm{OTf})_{2}$ (34), (Fig. 19). The amide proton can clearly be observed, and the amides bind in their neutral form to the iron centre by means of their carbonyl oxygen atoms, as was the case in $\mathbf{3 2}$ and 33. Surprisingly, both

Fig. 17. BAIP-derived $N, N, O$ amide ligands, with the Ph-DPAH ligand displayed for comparison.

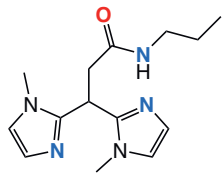

L1 AnPr

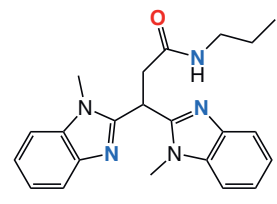

L2 $^{\text {AnPr }}$

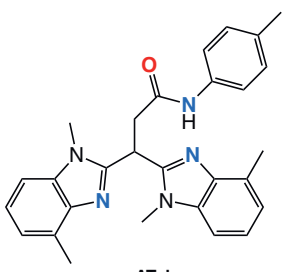

L4ATol

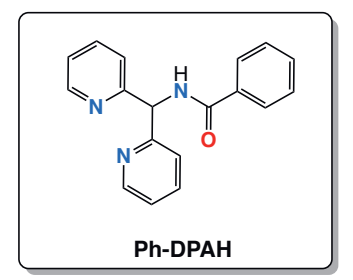

The coordination chemistry of $\mathbf{L} \mathbf{1}^{\mathrm{AnPr}}$ and $\mathbf{L} \mathbf{2}^{\mathrm{AnPr}}$ was explored in a study by Moelands et al. ${ }^{[57]}$ Reacting $\mathbf{L 1}^{\text {AnPr }}$ or $\mathbf{L} 2^{\text {AnPr }}$ with $\mathrm{Fe}(\mathrm{OTf}) \cdot 2 \mathrm{MeCN}$ in a 2:1 molar ratio in methanol afforded complexes 32 and 33, respectively, of the type $\left[\mathrm{Fe}^{\mathrm{II}}(\mathrm{L})_{2}\right](\mathrm{OTf})_{2}$ (Fig. 18). The crystal structures of the complexes reveal centrosymmetric, octahedral geometries in both cases, where the imidazole $N$-donors occupy the equatorial plane and the amide oxygen atoms coordinate on the axial positions, trans with respect to each other. As was previously observed in the bisligated ester complexes 23, 24 and 26, this particular orientation of the amide results in the tethered $n$-propyl groups pointing away from the metal centre, thereby exerting little effect on the geometry about the metal centre. The coordination of $\mathbf{L} 1^{\mathrm{AnPr}}$ and $\mathbf{L} \mathbf{2}^{\mathrm{AnPr}}$ is similar to that observed by Oldenburg et al. for complex $\left[\mathrm{Fe}^{\mathrm{II}}(\mathrm{Ph}-\right.$ DPAH $\left.)_{2}\right](\mathrm{OTf})_{2}$, where Ph-DPAH also coordinates facially, with the $O$-donors orientated trans with respect to each other ${ }^{[62]}$ The Fe-O bond lengths in 32 and 33 (2.157(5) $\AA$ and 2.0886(13) $\AA$, respectively) are somewhat shorter than those in 23-26, which range between 2.145(4) $\AA$ and 2.249(4) $\AA$. This might reflect the more strongly coordinating nature of the amide carbonyl groups compared to the ester ones. Cyclic voltammetry (CV) also revealed that 33 has a much lower $\mathrm{Fe}^{\mathrm{II}} / \mathrm{Fe}^{\mathrm{III}}$ oxidation potential $\left(\mathrm{E}_{\mathrm{p} . \mathrm{a}}\right.$ $=0.63 \mathrm{~V})$ than either 23 or $26\left(\mathrm{E}_{\mathrm{p}, \mathrm{a}}=0.82 \mathrm{~V}\right.$ and $0.95 \mathrm{~V}$, respectively).

In view of their greater affinity for (electrochemical) oxidation, complexes $\mathbf{3 2}$ and $\mathbf{3 3}$ were also tested as catalysts for oxidation of cyclooctene. However, both complexes were observed to exhibit low catalytic activity, which did not surpass the performance of the analogous ester complexes. A maximum of $5 \%$ and $8 \%$ in the conversion of $\mathrm{H}_{2} \mathrm{O}_{2}$ to oxidised products was obtained for 32 and 33, respectively (catalyst/oxidant/substrate ratio of 1:20:1000). Furthermore, 33 exhibited no selectivity towards either the epoxide or diol product. Although it is not unprecedented for non-heme iron complexes with mixed $\mathrm{N}, \mathrm{O}$-donor ligand sets to exhibit low turnover numbers, the low (or lack of) product selectivities obtained with $\mathbf{3 2}$ and $\mathbf{3 3}$ compared to Que's Ph-DPAH ligand molecules are bound by a facial $N, N, O$ coordination motif, each wrapped around the metal ion such that the amide carbonyl functionalities are cis to each other, which discredits the previous hypothesis that the bis(1,4-dimethylimidazole) scaffold only fa-

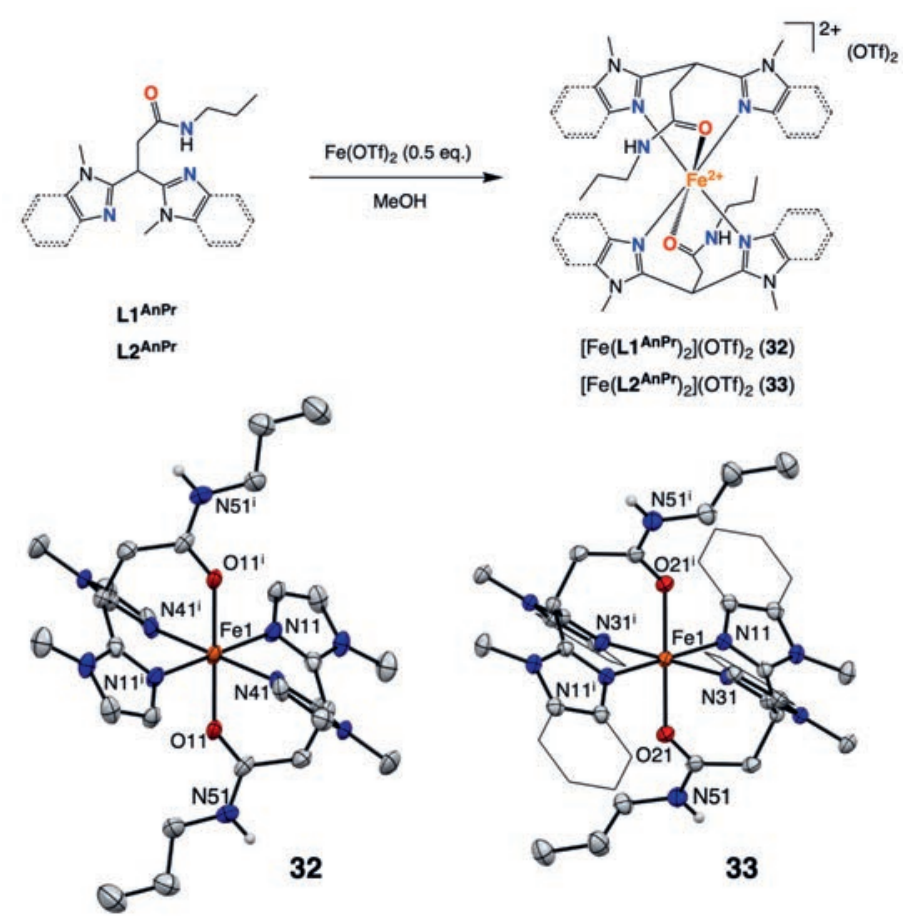

Fig. 18. Synthesis of complexes $\mathbf{3 2}$ and 33. Their respective crystal structures are also provided, with all $\mathrm{C}-\mathrm{H}$ hydrogen atoms and the non-coordinated OTf anions omitted for clarity. Displacement ellipsoids have been drawn at the $50 \%$ probability level. Aromatic rings of the benzimidazole substituents in $\mathbf{3} \mathbf{3}$ have been depicted in the wireframe format for clarity. ${ }^{[57]}$ 
vours monoligation. A similar result was obtained upon reaction of $\mathbf{L} 4^{\mathrm{ATTl}}$ with $\mathrm{FeCl}_{2}$ in a 1:1 stoichiometry, followed by the addition of a base to attempt deprotonating the amide groups. Crystals suitable for X-ray diffraction were obtained by slow evaporation of an acetonitrile solution of the product, but the crystal structure revealed that a mononuclear, monoligated iron(II) complex, $\left[\mathrm{Fe}^{\mathrm{II}}\left(\mathbf{L 4}^{\mathrm{ATol}}\right)(\mathrm{Cl})_{2}\right](\mathbf{3 5})$, had formed, very similar in structure to 29 (Fig. 19). The amide is protonated and therefore neutral, and is not bound to the iron centre. the accumulation of spin density on the ligand scaffold and could lead to biomimetic chemistry relevant to mononuclear non-heme enzymes such as intradiol cleaving dioxygenases (iron-based) ${ }^{[64]}$ or galactose oxidase (copper-based) ${ }^{[65]}$ that contain a tyrosinate residue at their active site.

Several pyrazole-derived $N, N, O$ phenolate ligands have been described in the literature, some of the most notable contributions of which come from the Carrano group. ${ }^{[47,66-68]}$ Our group has developed a series of similar imidazole-derived $N, N, O$ phenolate

Fig. 19. Synthesis of $\mathbf{3 4}$ and 35.

The crystal structures of the complexes are also provided, ${ }^{[63]}$ with $\mathrm{C}-\mathrm{H}$ hydrogen atoms omitted for clarity and displacement ellipsoids drawn at the $50 \%$ probability level. The non-coordinated OTf anions in $\mathbf{3 4}$ are not depicted, for clarity. Aromatic rings of the benzimidazole substituents in $\mathbf{3 4}$ are depicted in the wireframe format for clarity.

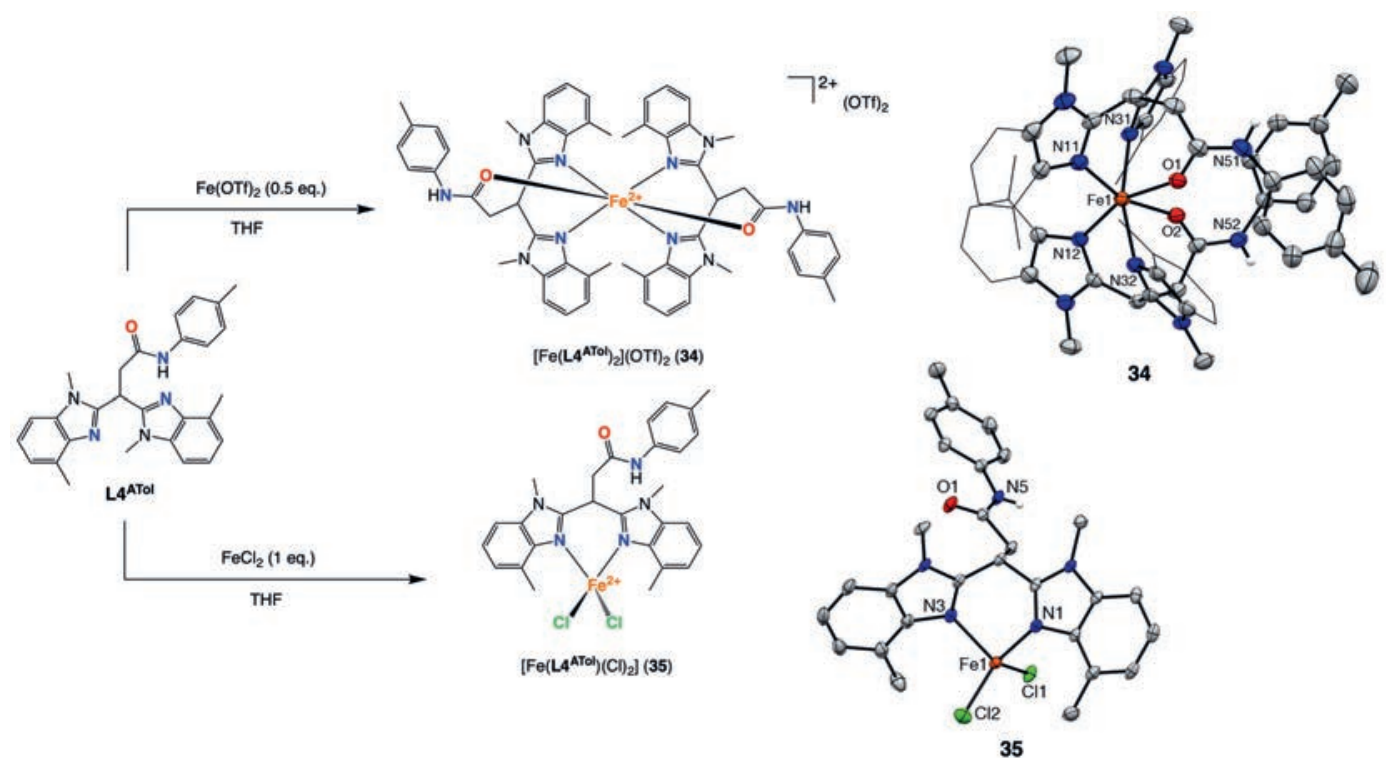

In summary, the BAIP-derived amide ligands show coordination chemistry similar to that observed for the ester family of ligands. The amide moiety can bind in its neutral form as an $O$-donor by means of its carbonyl oxygen atom. Coordination of the amide in this manner was observed to be sensitive to the nature of the counter anions present, where strongly binding anionic (e.g. chloride) promote amide coordination lability. To date, no successful attempts at deprotonating the amide have been made. It is therefore unknown whether this family of ligands could adopt an alternative anionic $N, N, N$ facial motif.

\subsection{Phenolate Ligands}

As previously mentioned, $N, N, O$ phenolate ligands are an attractive means with which to achieve anionic $O$-donor coordination while simultaneously having the option to tune the steric and electronic properties of the phenol ring by means of its ortho- and para-substituents. In some ways, this may be regarded as a convenient way to combine the advantages associated to the BAIP carboxylate and ester ligands, previously described in this review. However, the phenolate ligand design diverges significantly in terms of the redox non-innocence character associated to aromatic phenolate rings compared to acid and ester groups. The use of 3,5-disubstituted phenolates in particular may stabilise

ligands, depicted in Fig. 20. As can be seen, the connectivity of the phenolic oxygen atom within the ligand scaffold is iso-structural to that of the anionic oxygen atom of the BAIP carboxylate ligands. In addition, the phenolate ligands include a methoxy group, installed on the quaternary carbon backbone, which ensures that the only site available for deprotonation is the phenolic $\mathrm{O}-\mathrm{H}$ group.

The facial $N, N, O$ capping potential of ImNNO was first explored by Bruijnincx et al. in a study focused on the structural modelling of intradiol cleavage dioxygenase enzymes. ${ }^{[69]}$ Deprotonation of the ligand using $\mathrm{NEt}_{3}$, followed by reaction with half an equivalent of $\mathrm{Fe}\left(\mathrm{NO}_{3}\right)_{3} \cdot 9 \mathrm{H}_{2} \mathrm{O}$ afforded a high spin $(S$ $=5 / 2)$ bisligated iron complex, $\left[\mathrm{Fe}^{\mathrm{III}}(\operatorname{Im} \mathbf{N N O})_{2}\right]\left(\mathrm{NO}_{3}\right)(\mathbf{3 6})$. The crystal structure of the complex revealed that the iron has a distorted octahedral geometry and that the ligand molecules orientate themselves such that the phenolic oxygen atoms are positioned cis to each other (Fig. 21). As well as demonstrating the ability of the ligand to bind in the desired coordination mode, this complex demonstrates once again the ease with which two ligand equivalents can coordinate simultaneously in a $\kappa_{3}-N, N, O$ fashion to the metal ion.

The synthesis of iron(III) catecholato complexes supported by ImNNO was conducted according to the scheme depicted in Fig.
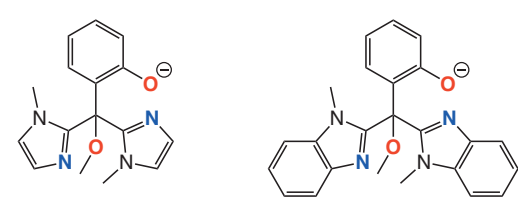

ImNNO

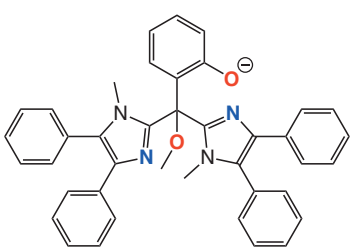

$\mathrm{Im}^{\mathrm{Ph} 2} \mathrm{NNO}$

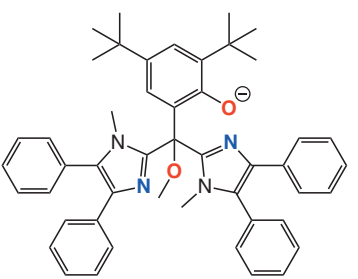

$\mathrm{Im}^{\mathrm{Ph} 2} \mathrm{NNO}^{\mathrm{tBu}}$
Fig. 20. The N,N,O phenolate ligands used in the group of Klein Gebbink. 


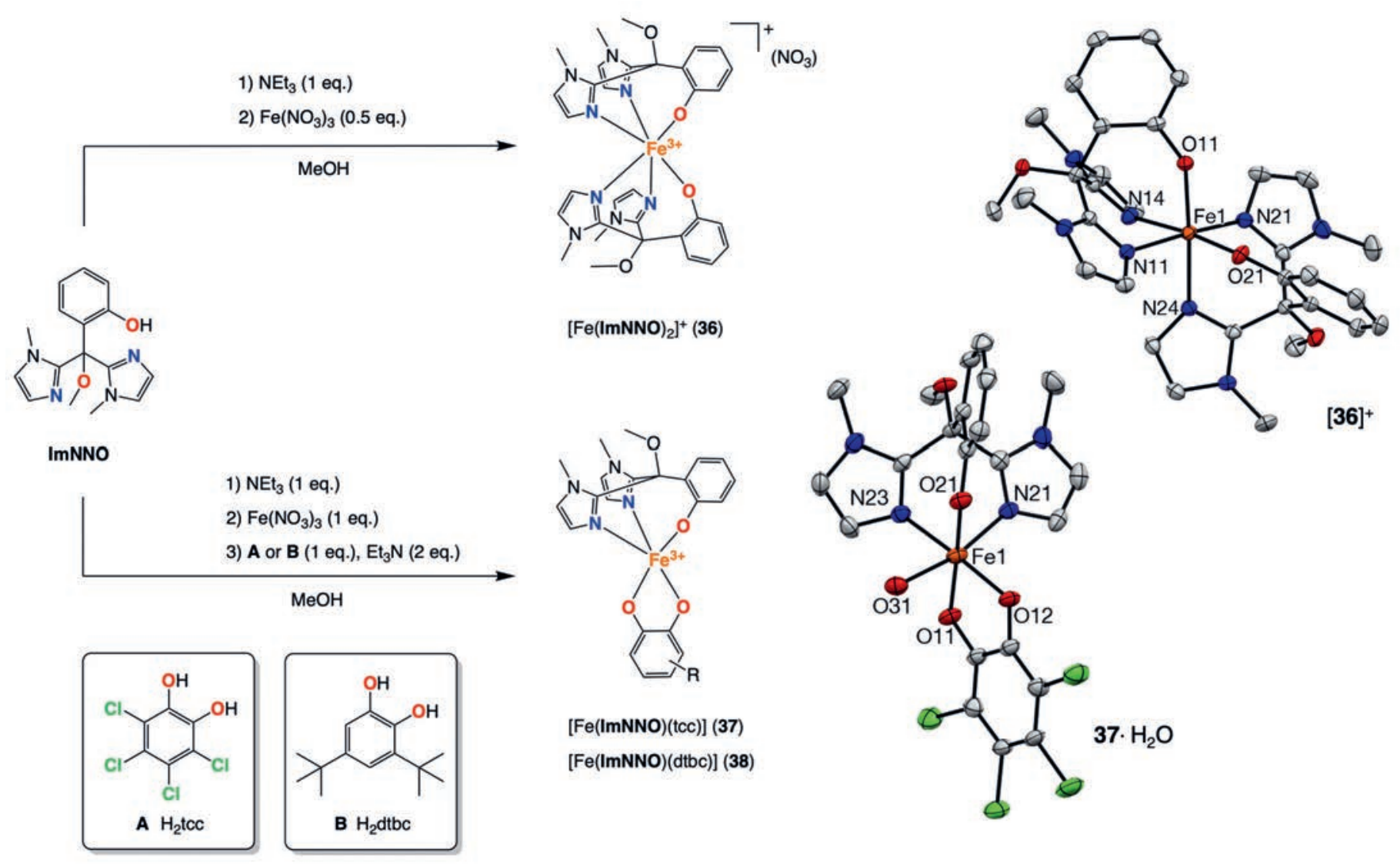

Fig. 21. Synthesis of complexes $\mathbf{3 6}-\mathbf{3 8}$. The crystal structures of $\mathbf{3 6}$ and $\mathbf{3 7} \cdot \mathrm{H}_{2} \mathrm{O}$ are also provided. $\mathrm{H}$-atoms have been omitted for clarity and displacement ellipsoids are drawn at the $50 \%$ probability level. The $\mathrm{NO}_{3}$ anion in 36 has been omitted for clarity. ${ }^{[69]}$

21 , which is similar to the method previously used for the synthesis of 8-19. On the basis of elemental analysis and EPR, complexes $\mathbf{3 7}$ and $\mathbf{3 8}$ were identified as neutral, pentacoordinate, high spin $(S=5 / 2)$ iron(III) complexes, whose coordination spheres feature the facial monoanionic $N, N, O$ coordination of ImNNO as well as the dianionic, bidentate coordination of the catecholate. The X-ray crystal structure of $\mathbf{3 7}$ confirmed the tridentate $N, N, O$ coordination of the supporting ligand as well as the bidentate coordination of the catecholate ligand. The co-crystallised water molecule is proposed to occupy the vacant coordination site of the iron centre, cis to the catecholate $O$-donors, which would be available for the binding of dioxygen. Overall the crystal structure obtained for $\mathbf{3 7} \cdot \mathrm{H}_{2} \mathrm{O}$ is very similar to that obtained for $\mathbf{1 6} \cdot \mathrm{H}_{2} \mathrm{O}$, with the only significant difference being, of course, the nature of the $O$-donor (Fig. 21). One of the most important differences is the longer $\mathrm{Fe}-\mathrm{O}$ (phenolato) bond in $37 \cdot \mathrm{H}_{2} \mathrm{O}(2.006(2) \AA)$ compared to the $\mathrm{Fe}-\mathrm{O}$ (carboxylate) bond in $\mathbf{1 6} \cdot \mathrm{H}_{2} \mathrm{O}(1.9516(18)$ $\AA)$. Overall, complexes $\mathbf{3 7}$ and $\mathbf{3 8}$ were established as some of the closest biomimetic structural models of an intradiol cleavage dioxygenase enzyme-substrate complex obtained to date.

The oxidation of $\mathbf{3 8}$ in air was studied by means of UV-vis, ${ }^{1} \mathrm{H}$ NMR and GC-MS, in both coordinating and non-coordinating solvents. Overall, the conversion of the catechol to oxidised products was observed to take place much more slowly than $\mathbf{1 9}$, only reaching full conversion after a period of approximately two weeks. This slow reactivity was ascribed to the quenching effect that the anionic mixed $N, O$-donor ligand scaffold has on the Lewis acidity of the ferric ion. Strikingly, the product distribution was seen to be much less dependent on the nature of the solvent used for the reaction compared to complexes 11-13. Furthermore, only approximately $10 \%$ of quinone formation (auto-oxidation product) was observed when conducting the reaction in acetonitrile, with $90 \%$ of the products deriving from oxidative cleavage reactivity. Overall, no preferential selectivity for either extradiol or intradiol cleavage products was observed, which enabled the conclusion to be made that the factors determining intradiol or extradiol cleavage reactivity in catechol cleaving dioxygenases must in part be determined by factors beyond the primary coordination sphere of the metal ion.

More recently, the coordination chemistry of the bulkier $N, N, O$ phenolates has been further explored using the more bulkier members of the ligand family, BenzImNNO, $\mathbf{I m}^{\mathrm{Ph} 2} \mathbf{N N O}$ and $\mathbf{I m}^{\mathrm{Ph} 2} \mathbf{N N O}^{\mathbf{t B u}}$. The results of these efforts will be summarised here.

Deprotonating BenzImNNO with $\mathrm{KH}$, followed by the addition of one equivalent of $\mathrm{ZnCl}_{2}$ afforded a dinuclear zinc(II) complex, $\left[\mathrm{Zn}_{2}(\mathrm{Phen})_{2}(\mathrm{Cl})_{2}\right]$ (39) (Fig. 22). From the crystal structure, one of the zinc ions is observed as having an octahedral geometry, bound by two $\mathrm{N}, \mathrm{N}, \mathrm{O}$-coordinating BenzImNNO molecules, arranged in cis fashion. The second zinc ion is tetrahedral in geometry, bound by two chloride ligands as well as the phenolato $O$-donors of the two ligand molecules. Retention of this structure in solution was confirmed by ESI-MS and ${ }^{1} \mathrm{H}$ NMR spectroscopy. The complex is iso-structural to a nickel(II) complex previously reported in the group of Carrano, involving an similar pyrazole-derived $N, N, O$ phenolate ligand.[66] It would seem, therefore, that the bisligated $\left[\mathrm{Zn}(\text { BenzImNNO })_{2}\right]$ complex is preferred from a thermodynamic point of view, and that the excess $\mathrm{ZnCl}_{2}$ in solution is stabilised by coordination of the phenolate $O$-donors, resulting in the overall dinuclear composition of $\mathbf{3 9}$.

An attempt was made to synthesise an iron(III) catecholato complex using a similar methodology to that previously described by Bruijnincx for the synthesis of $\mathbf{3 7}$ and 38. BenzImNNO was deprotonated with $\mathrm{KH}$ and subsequently reacted with anhydrous $\mathrm{FeCl}_{3}$ in THF for a period of $1 \mathrm{~h}$, before the addition of a premixed THF solution of catechol (cat) and $\mathrm{NEt}_{3}$ (in 2:1 stoichiometry). Crystals suitable for X-ray crystallography were obtained from slow evaporation of a $\mathrm{CH}_{2} \mathrm{Cl}_{2}$ solution of the product at low 


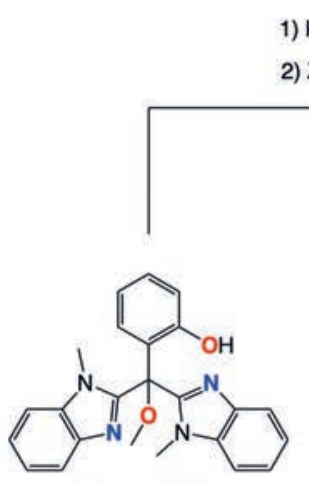

1) $\mathrm{KH}(1.2$ eq.)

2) $\mathrm{ZnCl}_{2}$ (1 eq.)

THF

BenzimNNO

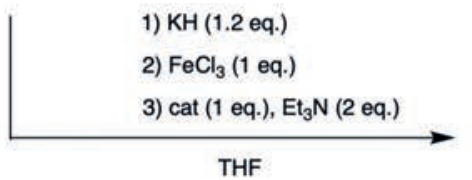

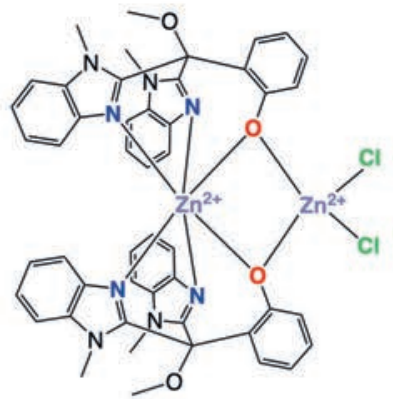

$\left[\mathrm{Zn}_{2}(\text { BenzlmNNO })_{2}(\mathrm{Cl})_{2}\right](39)$

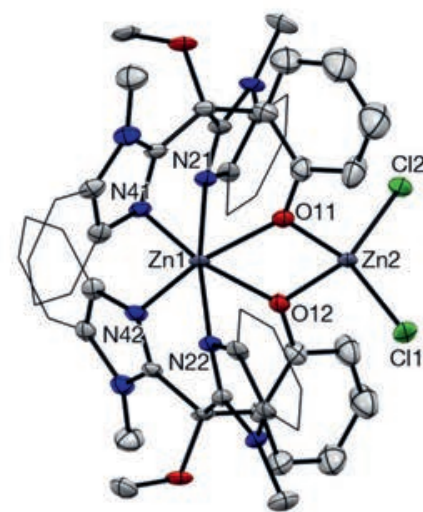

39

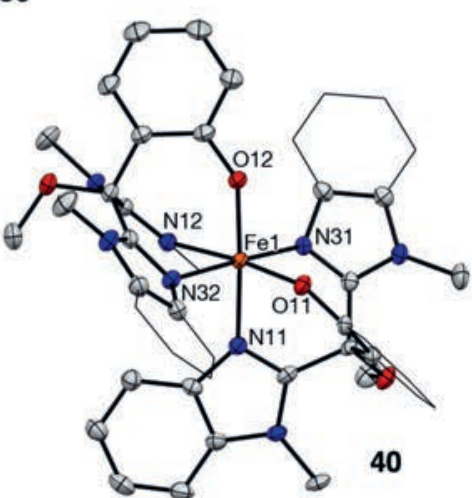

$\left[\mathrm{Fe}_{2}(\mathrm{BenzImNNO})_{2}\right]\left[\mathrm{Fe}_{2}(\mathrm{Cat})_{2}(\mathrm{Cl})_{4}\right](\mathbf{4 0})$

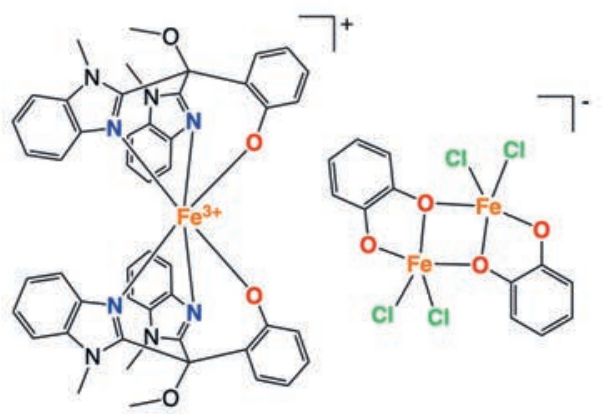

Fig. 22. Synthesis of complexes $\mathbf{3 9}$ and $\mathbf{4 0}$. Crystal structures are also provided, ${ }^{[70]}$ with $\mathrm{H}$-atoms omitted for clarity and displacement ellipsoids drawn at the $50 \%$ probability level. The aromatic rings of the benzimidazole substituents are depicted in the wireframe format for clarity. The counter anion in $\mathbf{4 0}$ is omitted for clarity.

temperature. The crystal structure reveals, rather surprisingly, that a cationic iron(III) bisligated complex, $\left[\mathrm{Fe}^{\mathrm{III}}(\text { BenzImNNO})_{2}\right]^{+}$ (40), had formed that is very similar in structure to the cationic complex 36 previously reported by Bruijnincx et al. The counter anion to the complex, $\left[\mathrm{Fe}_{2}(\mathrm{cat})_{2}(\mathrm{Cl})_{4}\right]$, evidently formed in situ. Its structure indicates that the catechol acted as a scavenger for the excess iron(III) in solution and that it was therefore unable to promote the formation of a mononuclear [Fe(L)(cat)]-type complex, as was initially intended. Presumably, the formation of a bisligated $\left[\mathrm{Fe}^{\mathrm{III}}(\mathrm{L})_{2}\right]^{+}$is thermodynamically favourable and occurs very fast in solution. The increased steric bulk of BenzImNNO also means that the iron nucleus is relatively inaccessible for co-ligand molecules upon formation of a bisligated complex.

Currently, our group is investigating the coordination chemistry of the two bulkiest $N, N, O$ phenolate ligands, $\mathbf{I m}^{\mathrm{Ph}} \mathbf{N N O}$ and $\mathbf{I m}^{\mathbf{P h} 2} \mathbf{N N O}^{\text {tBu }}$ (Fig. 23). Preliminary results indicate that both ligands are capable of coordinating by means of the desired $N, N, O$ facial triad to divalent metal ions. In the case of $\mathbf{I m}^{\mathbf{P h} 2} \mathbf{N N O}$, dinuclear complexes are obtained where each metal is tetrahedral in geometry, bound by the $N, N, O$ donor set as well as an anionic ligand (e.g. triflate). In the case of $\mathbf{I m}^{\mathrm{Ph} 2} \mathbf{N N O}^{\mathbf{t B u}}$, mononuclear, monoligated complexes are obtained. These complexes are bound by the desired facial $N, N, O$ donor set of the ligand scaffold as well as an anionic ligand (e.g. chloride). The substitutional lability of the triflate or chloride ligands for biorelevant cofactors (for example, monodentate thiolates) is currently being investigated. Full details of these studies will be communicated in due time.

\section{Conclusion}

Our group has focused on the design of the facial $N, N, O$ ligands derived from the so-called 'BAIP' ligand scaffold, which incorporate the biologically relevant imidazole heterocycle, as well as a range of different $O$-donors, including carboxylates, esters, secondary amides and phenolates. These ligands have been designed to model the structural features of the $2 \mathrm{H} 1 \mathrm{C}$ as closely as possible.

By varying the nature of the steric component of the imidazole heterocycle as well as the nature of the $O$-donor, the geometric and electronic properties of the resulting metal complexes can be tuned, and therefore their reactivity and performance in ca-
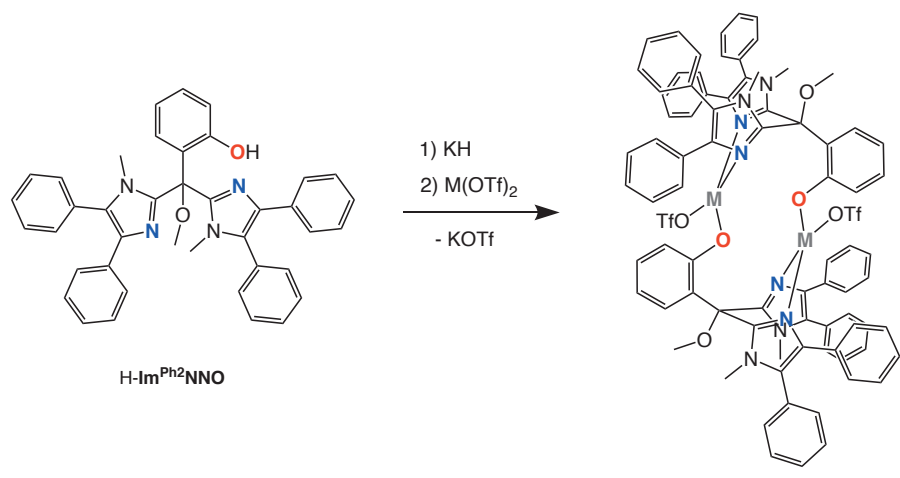

$\left[\mathrm{M}_{2}\left(\mathrm{Im}^{\mathrm{Ph} 2} \mathrm{NNO}\right)_{2}(\mathrm{OTf})_{2}\right]$
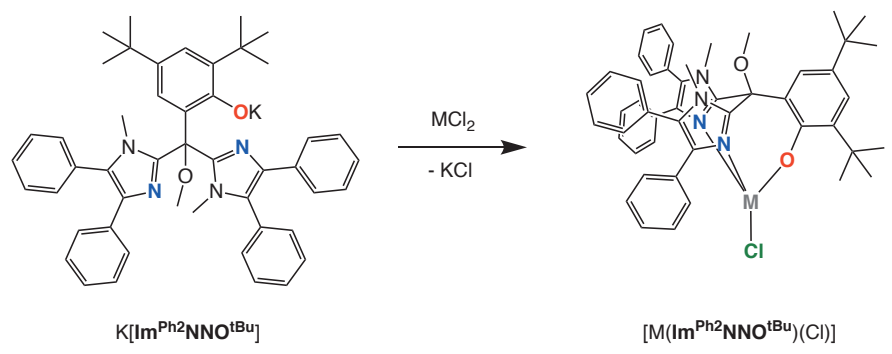

Fig. 23. The synthesis of dinuclear and mononuclear non-heme metal complexes using $\mathrm{Im}^{\mathrm{Ph} 2} \mathrm{NNO}$ and $\mathrm{Im}^{\mathrm{Ph} 2} \mathrm{NNO}^{\mathrm{tBu}}$. 
talysis can also be modulated. Generally, it has been observed that increasing the steric bulk on the imidazole heterocycles is the most promising method towards the formation of thermodynamically stable monoligated complexes. Alternatively, a coligand can be used to inhibit the formation of bisligated complexes. Mononuclear, monoligated complexes that feature the desired facial $N, N, O$ coordination of the supporting ligand have been obtained for BAIP carboxylate, ester and phenolate ligands.

Some reactivity studies have been conducted for the complexes that were successfully able to structurally model the substrate-bound active sites of intra- and extradiol cleaving catechol dioxygenase enzymes. However, no particular trends in selectivity for either intra- or extradiol cleavage reactivity were observed, which led to the conclusion that the enzyme selectivity is also determined by factors greater than simply the first coordination sphere of the enzyme active site. Catalytic tests involving bisligated BAIP ester-bound iron complexes (e.g. complex 23) show the ability to catalyse both cis-dihydroxylation as well as epoxidation of olefins. To date, these complexes constitute members of a small, select family of non-heme iron(II) complexes bound to tridentate $N, N, O$ ligands that exhibit such reactivity.

Overall, the work described in this review shows that further exploration of the coordination chemistry and reactivity of nonheme iron complexes featuring facial $N, N, O$ ligands remains a highly attractive field of research, as there are still many aspects of the reactivity and selectivity exhibited by $2 \mathrm{H} 1 \mathrm{C}$-containing non-heme iron enzymes that are not yet understood such as the role that the anionic carboxylate donor may be playing in determining oxidase or oxygenase reactivity. With the diverse family of BAIP-derived $N, N, O$ ligands at hand, the current status in the development of the ligands enables us to carry out dedicated coordination chemistry and spectroscopic studies in order to mimic specific enzyme active site structural parameters and possibly address trends in the reactivity exhibited by the different classes of 2H1C-containing mononuclear non-heme iron enzymes.

\section{Acknowledgements}

E.C.M. and B.K.G gratefully acknowledge the financial support provided by the European Union, under the NoNoMeCat 675020-MSCAITN-2015 grant agreement. X-ray diffractometer was financed by The Netherlands Organization for Scientific Research (NWO).

Received: April 16, 2020

[1] W. Kaim, B. Schwederski, A. Klein, in 'Bioinorganic Chemistry: Inorganic Elements in the Chemistry of Life', Wiley, 1994, pp. 1-426.

[2] M. Costas, M. P. Mehn, M. P. Jensen, L. Que Jr., Chem. Rev. 2004, 104, 939.

[3] P. C. A. Bruijnincx, G. Van Koten, R. J. M. Klein Gebbink, Chem. Soc. Rev. 2008, 37, 2716.

[4] K. Degtyarenko, Bioinformatics 2000, 16, 851.

[5] R. H. Holm, P. Kennepohl, E. I. Solomon, Chem. Rev. 1996, 96, 2239.

[6] M. F. Perutz, M. G. Rossmann, A. F. Cullis, H. Muirhead, G. Will, A. C. T. North, Nature 1960, 185, 416

[7] M. F. Perutz, Science 1963, 140, 863.

[8] K. J. Waldron, J. C. Rutherford, D. Ford, N. J. Robinson, Nature 2009, 460, 823

[9] K. J. Waldron, N. J. Robinson, Nat. Rev. Microbiol. 2009, 7, 25.

[10] L. J. Que, Nat. Struct. Biol. 2000, 7, 182.

[11] S. Kal, L. Que, J. Biol. Inorg. Chem. 2017, 22, 1.

[12] K. D. Koehntop, J. P. Emerson, L. Que, J. Biol. Inorg. Chem. 2005, 10, 87.

[13] S. P. de Visser, G. D. Straganz, J. Phys. Chem. A 2009, 113, 1835.

[14] J. C. Price, E. W. Barr, B. Tirupati, M. J. Bollinger Jr., C. Krebs, Biochemistry 2003, $42,7497$.

[15] E. Tamanaha, B. Zhang, Y. Guo, W. Chang, E. W. Barr, G. Xing, J. St. Clair, S. Ye, F. Neese, J. M. Bollinger, C. Krebs, J. Am. Chem. Soc. 2016, 138, 8862.

[16] C. Krebs, D. Galonic Fujimori, C. T. Walsh, J. M. Bollinger, Acc. Chem. Res. 2007, 40, 484

[17] K. Valegård, A. C. T. van Scheltinga, M. D. Lloyd, T. Hara, S. Ramaswamy, A. Perrakis, A. Thompson, H.-J. Lee, J. E. Baldwin, C. J. Schofield, J. Hajdu, I. Andersson, Nature 1998, 394, 805.
[18] M. W. Vetting, L. P. Wackett, L. Que, J. D. Lipscomb, D. H. Ohlendorf, J. Bacteriol. 2004, 186, 1945.

[19] J. R. O'Brien, D. J. Schuller, V. S. Yang, B. D. Dillard, W. N. Lanzilotta, Biochemistry 2003, 42, 5547.

[20] P. L. Roach, I. J. Clifton, C. M. H. Hensgens, N. Shibata, C. J. Schofield, J. Hajdu, J. E. Baldwin, Nature 1997, 387, 827.

[21] M. Swart, M. Costas, in 'Spin States in Biochemistry and Inorganic Chemistry', Wiley, 2016, pp. 1-448

[22] M. Costas, J. N. Harvey, Nature 2013, 5, 7 .

[23] E. J. Blaesi, B. G. Fox, T. C. Brunold, Biochemistry 2015, 54, 2874

[24] R. Kreisberg-Zakarin, I. Borovok, M. Yanko, F. Frolow, Y. Aharonowitz, G. Cohen, Biophys. Chem. 2000, 86, 109.

[25] H. Park, D. Lee, Chem. Eur. J. 2020, 26, 1.

[26] D. Sheet, T. K. Paine, Chem. Sci. 2016, 7, 5322

[27] J. B. Gordon, A. C. Vilbert, I. M. DiMucci, S. N. MacMillan, K. M. Lancaster, P. Moënne-Loccoz, D. P. Goldberg, J. Am. Chem. Soc. 2019, 141 , 17533.

[28] M. Puri, L. Que, Acc. Chem. Res. 2015, 48, 2443

[29] Y.-M. Chiou, L. Que, J. Am. Chem. Soc. 1995, 117, 3999.

[30] G. J. P. Britovsek, J. England, A. J. P. White, Inorg. Chem. 2005, 44, 8125.

[31] A. N. Biswas, M. Puri, K. K. Meier, W. N. Oloo, G. T. Rohde, E. L. Bominaar, E. Münck, L. Que, J. Am. Chem. Soc. 2015, 137, 2428

[32] V. Dantignana, J. Serrano-Plana, A. Draksharapu, C. Magallón, S. Banerjee, R. Fan, I. Gamba, Y. Guo, L. Que, M. Costas, A. Company, J. Am. Chem. Soc. 2019, 141, 15078.

[33] J. Chen, R. J. M. Klein Gebbink, ACS Catal. 2019, 9, 3564.

[34] A. Otero, J. Fernández-Baeza, A. Antiñolo, J. Tejeda, A. Lara-Sánchez, Dalton Trans. 2004, 1499.

[35] M. A. H. Moelands, D. J. Schamhart, E. Folkertsma, M. Lutz, A. L. Spek, R. J. M. Klein Gebbink, Dalton Trans. 2014, 43, 6769.

[36] P. J. Cappillino, J. R. Miecznikowski, L. A. Tyler, P. C. Tarves, J. S. McNally, W. Lo, B. S. T. Kasibhatla, M. D. Krzyaniak, J. McCracken, F. Wang, W. H. Armstrong, J. P. Caradonna, Dalton Trans. 2012, 41, 5662.

[37] E. Hübner, N. V. Fischer, R. W. Heinemann, U. Mitra, V. Dremov, P. Müller, N. Burzlaff, Eur. J. Inorg. Chem. 2010, 4100.

[38] I. Hegelmann, A. Beck, C. Eichhorn, B. Weibert, N. Burzlaff, Eur. J. Inorg. Chem. 2003, 339 .

[39] L. Peters, N. Burzlaff, Polyhedron 2004, 23, 245

[40] P. Ghosh, G. Parkin, J. Chem. Soc. Dalton Trans. 1998, 2281

[41] C. G. Young, M. S. Malarek, D. J. Evans, C. J. Doonan, V. W. L. Ng, J. M. White, Inorg. Chem. 2009, 48, 1960

[42] D. D. Cox, S. J. Benkovic, L. M. Bloom, F. C. Bradley, M. J. Nelson, L. Que, D. E. Wallick, J. Am. Chem. Soc. 1988, 110, 2026.

[43] K. Sundaravel, E. Suresh, K. Saminathan, M. Palaniandavar, Dalton Trans. 2011, 40, 8092 .

[44] P. D. Oldenburg, C.-Y. Ke, A. A. Tipton, A. A. Shteinman, L. Que, Angew. Chemie Int. Ed. 2006, 45, 7975.

[45] A. Beck, B. Weibert, N. Burzlaff, Eur. J. Inorg. Chem. 2001, 521.

[46] S. M. Barry, H. Mueller-Bunz, P. Rutledge, J. Org. Biomol. Chem. 2012, 10, 7372 .

[47] J. N. Smith, Z. Shirin, C. J. Carrano, J. Am. Chem. Soc. 2003, 125, 868.

[48] D. L. Jameson, S. E. Hilgen, C. E. Hummel, S. L. Pichla, Tetrahedron Lett. 1989, 30,1609

[49] P. C. A. Bruijnincx, M. Lutz, A. L. Spek, E. E. van Faassen, B. M. Weckhuysen, G. van Koten, R. J. M. Klein Gebbink, Eur. J. Inorg. Chem. $2005,779$.

[50] P. C. A. Bruijnincx, M. Lutz, J. P. den Breejen, A. L. Spek, G. van Koten, R. J. M. Klein Gebbink, J. Biol. Inorg. Chem. 2007, 12, 1181.

[51] P. C. A. Bruijnincx, I. L. C. Buurmans, S. Gosiewska, M. A. H. Moelands, M. Lutz, A. L. Spek, G. Van Koten, R. J. M. Klein Gebbink, Chem. Eur. J. 2008, 14, 1228

[52] L. Peters, E. Hübner, N. Burzlaff, J. Organomet. Chem. 2005, 690, 2009

[53] S. S. Rocks, W. W. Brennessel, T. E. Machonkin, P. L. Holland, Inorg. Chim. Acta 2009, 362, 1387.

[54] P. C. A. Bruijnincx, M. Lutz, A. L. Spek, W. R. Hagen, B. M. Weckhuysen, G. Van Koten, R. J. M. Klein Gebbink, J. Am. Chem. Soc. 2007, 129, 2275.

[55] E. Folkertsma, PhD Thesis, 'Iron and Zinc Complexes of Bulky BisImidazole Ligands Enzyme Mimicry and Ligand-Centered Redox Activity', Utrecht University, 2016.

[56] CCDC 1996783 contains the supplementary crystallographic data for complex 22. These data can be obtained free of charge from The Cambridge Crystallographic Data Centre via www.ccdc.cam.ac.uk/structures

[57] M. A. H. Moelands, S. Nijsse, E. Folkertsma, B. De Bruin, M. Lutz, A. L. Spek, R. J. M. Klein Gebbink, Inorg. Chem. 2013, 52, 7394.

[58] E. Folkertsma, E. F. de Waard, G. Korpershoek, A. J. van Schaik, N. Solozabal Mirón, M. Borrmann, S. Nijsse, M. A. H. Moelands, M. Lutz, M. Otte, M.-E. Moret, R. J. M. Klein Gebbink, Eur. J. Inorg. Chem. 2016, 9, 1319.

[59] Y. Uragami, T. Senda, K. Sugimoto, N. Sato, V. Nagarajan, E. Masai, M. Fukuda, Y. Mitsui, J. Inorg. Biochem. 2001, 83, 269.

[60] A. W. Addison, T. N. Rao, J. Reedijk, J. van Rijn, G. C. Verschoor, J. Chem. Soc., Dalton Trans. 1984, 1349. 
[61] CCDC 1996781 and CCDC 1996782 contain the supplementary crystallographic data for complexes $\mathbf{3 0}$ and $\mathbf{3 1}$, respectively. These data can be obtained free of charge from The Cambridge Crystallographic Data Centre via www.ccdc.cam.ac.uk/structures

[62] P. D. Oldenburg, A. A. Shteinman, L. Que, J. Am. Chem. Soc. 2005, 127 15672 .

[63] CCDC 1996784 and CCDC 1996785 contain the supplementary crystallographic data for complexes $\mathbf{3 4}$ and $\mathbf{3 5}$, respectively. These data can be obtained free of charge from The Cambridge Crystallographic Data Centre via www.ccdc.cam.ac.uk/structures

[64] F. H. Vaillancourt, J. T. Bolin, L. D. Eltis, Crit. Rev. Biochem. Mol. Biol. 2006, 41,241

[65] N. Ito, S. E. V. Phillips, K. D. S. Yadav, P. F. Knowles, J. Mol. Biol. 1994 $238,794$.

[66] T. C. Higgs, C. J. Carrano, Inorg. Chem. 1997, 36, 298

[67] B. S. Hammes, C. J. Carrano, Inorg. Chem. 1999, 38, 4593.

[68] B. S. Hammes, C. J. Carrano, Inorg. Chem. 1999, 38, 3562.

[69] P. C. A. Bruijnincx, M. Lutz, A. L. Spek, W. R. Hagen, G. van Koten, R. J. M. Klein Gebbink, Inorg. Chem. 2007, 46, 8391.

[70] CCDC 1996786 and CCDC 1996787 contain the supplementary crystallographic data for complexes 39 and $\mathbf{4 0}$, respectively. These data can be obtained free of charge from The Cambridge Crystallographic Data Centre via www.ccdc.cam.ac.uk/structures

\section{License and Terms}

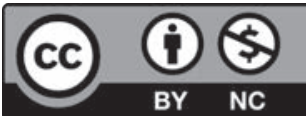

This is an Open Access article under the terms of the Creative Commons Attribution License CC BY_NC 4.0. The material may not be used for commercial purposes.

The license is subject to the CHIMIA terms and conditions: (http:// chimia.ch/component/sppagebuilder/?view=page $\& i d=12$ ).

The definitive version of this article is the electronic one that can be found at doi:10.2533/chimia.2020.450. 